\title{
Sobre bicicletas y otros encantos cinematográficos
}

Reto Melchior

Doutor pela Universidade de São Paulo

Kollegium St. Fidelis Stans, Suiça 


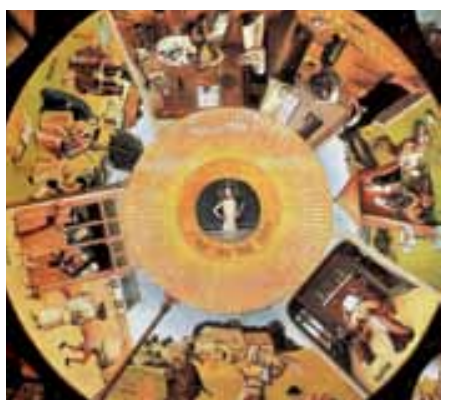

El Bosco (Hieronymus Bosch):

(Los pecados capitales, 1485)

\section{Resumo}

Abordagem interpretativa da personagem do ciclista de Un Chien Andalou (1929), de Luis Buñuel e Salvador Dalí. Além da alusão do título ao poeta andaluz, considera-se esta cena de um homem ridículo andando de bicicleta como o momento chave do escárnio contra Federico García Lorca, por se fundamentar no "diálogo" El paseo de Buster Keaton (1925): texto de índole íntima que o próprio autor, em época de mútua confiança, tinha enviado a Dalí.

\section{Palavras-chave}

Cinema e literatura, Intertextualidade, Percepção associativa, Buñuel/ Dalí, Un Chien Andalou, Federico García Lorca, Buster Keaton

\section{Abstract}

Interpretative approach to the character of the cyclist in Un Chien andalou (1929), by Luis Buñuel and Salvador Dalí. Besides the title, this scene with a ridiculous man riding a bicycle is considered the main point of derision against Federico García Lorca because it is founded upon a "dialogue" by the Spanish writer, El paseo de Buster Keaton (1925), full of personal allusions, that the author, in moments of mutual confidence, had sent to Dalí.

\section{Key words}

Cinema and literature, Intertextuality, Associative perception, Buñuel / Dalí, Un Chien andalou, Federico García Lorca, Buster Keaton 


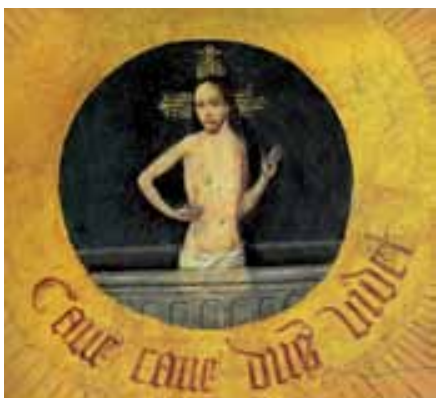

"Cave cave, Dominus videt" (detalle de Los pecados capitales)

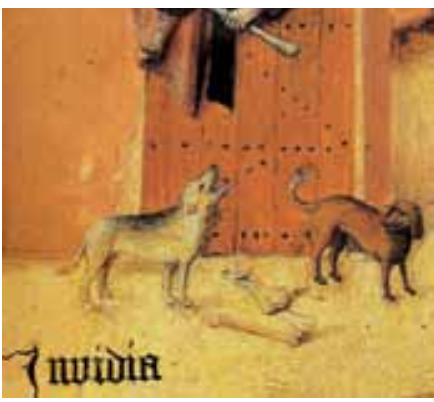

"Invidia"

(detalle de Los pecados capitales)

\section{Sobre ciclistas y perros invisibles}
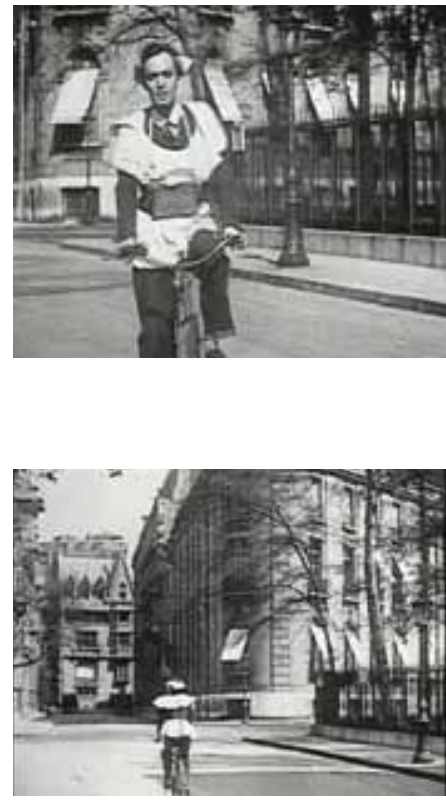

1 Parece que Lorca le dijo a su amigo Ángel del Río: „Buñuel ha hecho una mierdesita así de pequeñita que se llama Un perro andaluz y el perro andaluz soy yo “(PÉREZ TURRENT

/ DE LA COLINA, 1993: 21).
Parece que las bicicletas tienen un atractivo muy particular para la especie canina. Así cuando pasa un hombre en bicicleta por una zona bajo la custodia de un perro guardián, éste se levanta y corre tras el intruso. No se sabe si el cuadrúpedo quiere morder el pie del ciclista por puro placer o porque lo considera un peligro, si es una acción espontánea con objetivo de espantar a un potencial enemigo de su área de influencia o si la reacción agresiva se explica por un encanto secreto que emana de la bicicleta o del ciclista.

Cada vez que veo la escena de Un Chien andalou (Un perro andaluz, 1929) en la que Pierre Batcheff pasa en bicicleta por las calles de París (es decir, por la misma calle en direcciones opuestas...), me temo que le salga, desde algún ángulo escondido, un perro ladrador con ganas de asustarlo o pegarle un mordisco. Claro, lo sabemos todos: no hay ningún perro en toda la película, y esto precisamente es uno de los factores de extrañamiento del cortometraje surrealista. Sin embargo, sabemos también que al final de la escena, el ciclista se cae del vehículo sin motivo evidente como si hubiera por ahí cerca, invisible, un canino ladrando.

Esa escena del ciclista ha sido harto comentada, y no cabe duda alguna de que Un Chien andalou implica un ajuste de cuentas por parte de Luis Buñuel y Salvador Dalí con Federico García Lorca. El golpe bajo del cineasta boxeador, respaldado por el joven pintor que el poeta granadino tanto había querido, lo vulneró gravemente. El mensaje subliminal de la película selló la ruptura de la amistad, y Lorca comprendió perfectamente: el perro soy yo. ${ }^{1}$ Mucho después 
del asesinato del poeta granadino en 1936, Buñuel se defendió contra tal imputación: "No es así. La gente encuentra alusiones donde quiere si se empeña en sentirse aludida" (PÉREZ TURRENT / DE LA COLINA, 1993: 21).

2. Véase el capítulo "Secretos de alcoba" en Dalí joven, Dalí genial (GIBSON, 2004: 162-166).

3. “¿El perro andaluz era Lorca? La acusación estaba justificada (aunque

Buñuel la negaría después, y cabe pensar que se basaba sobre todo en tres secuencias del guión. / En primer lugar, la escena en que el afeminado protagonista masculino se materializa de repente sobre la cama y 'vuelve a la vida', transparente alusión a las representaciones que hacía Lorca de su propia muerte y resurrección, y que tanto habían impresionado a Dalí. / Luego la escena de la bicicleta [...]. En el breve texto, salpicado de alusiones al cine, un afeminado Buster Keaton no sólo se cae de su bicicleta, sino que fracasa rotundamente en dos encuentros heterosexuales. En una palabra, es impotente, condición que

Buñuel atribuía a Lorca. [...] / En tercer lugar, es probable que Lorca sospechara otra alusión a su persona en el extraordinario inicio, intensa-

mente erótico, de la secuencia en que el protagonista intenta seducir a la muchacha. [...] La angustia que se refleja en el rostro del personaje al ver los pechos desnudos de la muchacha puede reflejar el horror que Lorca sentía por los senos (así como Dalí, y que el pintor recordaría muchos años después: mientras el placer que experimenta el protagonista al acariciar las nalgas de la chica (no los muslos) pretende seguramente aludir una vez más a la homosexualidad sugerida por la boca-esfínter del guión" (GIBSON,

No voy a entrometerme aquí en esos marañosos bastidores de amores y celos que tanto habían marcado las relaciones entre Lorca, Dalí y Buñuel durante la época en que los tres vivían juntos en la Residencia de Estudiantes de Madrid; los "secretos de alcoba" han sido suficientemente comentados, de modo que ya no hay secretos. ${ }^{2}$ Lorca, sin embargo, debe de haberse exasperado porque la escena del ciclista está sin duda inspirada en un texto suyo, un "diálogo" surrealista, escrito en 1925 y publicado en 1929 bajo el título El paseo de Buster Keaton, texto que -según Ian Gibson- refleja "la angustia sexual del escritor". 3

En su libro Lorca-Dalí el amor que no pudo ser, el historiador y biógrafo irlandés esboza los puntos que el diálogo lorquiano y el cortometraje tienen en común, llegando a la conclusión de que "parece imposible dudar que al crear al protagonista masculino de Un Chien andalou Buñuel y Dalí no estuvieran pensando realmente en Lorca” (GIBSON, 1999: 249).

Esa identificación de Lorca con el ciclista -y al mismo tiempo con el perro andaluz anunciado en el título de la película- me lleva a formular la siguiente tesis: el perro existe. ${ }^{4}$ Es un cuadrúpedo que ladra (el cine mudo nunca fue silencioso...), un perro de caza español que se esconde detrás de la cámara: se trata del dúo Buñuel y Dalí que, como las bestias del infierno pintadas por El Bosco, caza al Buster Keaton lorquiano afeminado y puesto en ridículo, como el perrillo faldero en el cuadro de Philip Reinagle, que toca el piano.

Mejor dicho, Un Chien andalou es una película con tres perros: dos de caza escondidos detrás de la cámara (un aragonés y un catalán) y la estrella -un perro andaluz adiestrado- que monta en bicicleta.
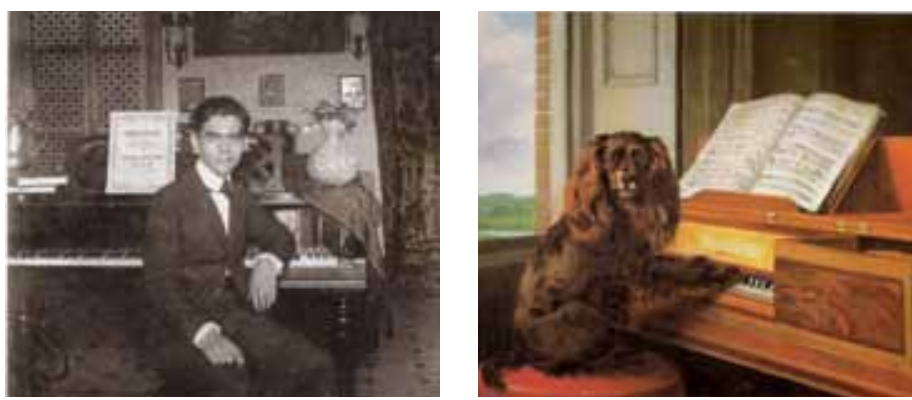

1999: 247-248). 


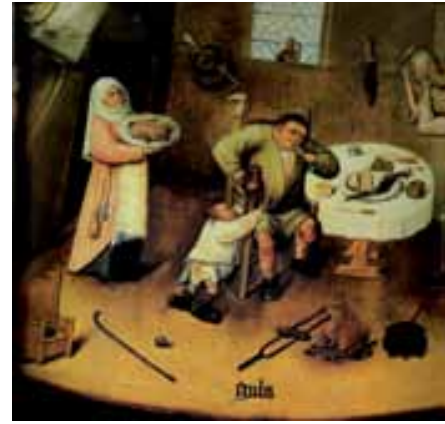

El Bosco (Hieronymus Bosch): "Gula" (detalle de Los pecados capitales, 1485)
4. Véase mi comentario sobre esta inversión interpretativa, fundamentada en un punto de partida diferente (el cuadro El enigma sin fin, de 1938, en que Dalí junta el retrato de Lorca con la silueta de un perro, con la obra de Joan Miró, Perro ladrándole a la luna, de 1926, y con otros cuadros) en el capítulo „O dialogismo com Un Chien andalou" en: Viaje a la luna: uma biografia em projeção (MELCHIOR, 2008: 134-161). Generalmente se ha considerado ese único guión lorquiano como una respuesta al cortometraje en discusión.

\section{Sobre casamientos y cisnes}

Los estudiantes de la Residencia adoraban el cine. "Federico, Alberti, Dalí y yo íbamos mucho al cine, para reírnos con los Keaton, los Ben Turpin, los Ambrosios. Sobre todo Keaton", comenta el cineasta aragonés (BUÑUEL, 1982: 277). En la Residencia había un cineclub bien frecuentado, y el cine fue tema de discusión diario. Buñuel escribía reseñas (sobre Metrópolis, La dama de las camelias, Napoleón Bonaparte... $)^{5}$ y Rafael Alberti, otro compañero andaluz de la Residencia, hizo poemas inspirados por las estrellas del cine mudo (Charlot, Harold Lloyd, Harry Langdon, Stan Laurel, Oliver Hardy...). El interés que Keaton suscitó en la generación de Lorca está ampliamente documentado, y los comentaristas hablan de “apasionados admiradores de Keaton” (GIBSON, 1999: 127).

Los biógrafos saben también que en aquel verano de 1925, Salvador Dalí y Lorca estaban unidos como nunca. ${ }^{6}$ Agustín Sánchez Vidal escribe en su ensayo "Dalí-Buñuel: encuentros y desencuentros" (en: ¡Ola Pepín!..., 2007: 25): "En cuanto a la relación entre Lorca y Dalí, alcanza su plenitud en ausencia de Buñuel, cuando éste se traslada a París en enero de 1925. Y queda plasmada en la Oda a Salvador Dalí (1926) del poeta y la colaboración del pintor en los decorados de Mariana Pineda (1927)".

Para mejor entender la génesis del texto lorquiano sobre Keaton, las investigaciones biográficas de Gibson nos dan las siguientes informaciones reveladoras: "En una fecha imposible de determinar con

5. La mayoría de esos textos fueron publicados en 1927. Véase los "escritos cinematográficos” (en: BUÑUEL, 1982: 149-180).
6. Véase Dalí joven, Dalí genial (GIBSON 2004: 162-166).

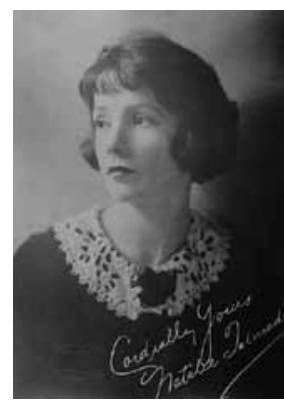

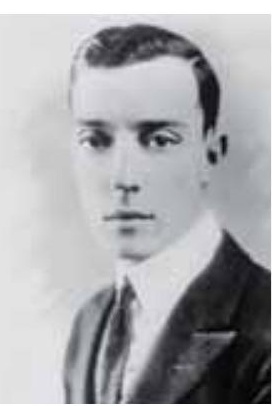


precisión pero verosímilmente de 1925, Dalí le envía a Federico un collage suyo titulado El casamiento de Buster Keaton, compuesto de recortes de periódicos - fotografías de Pamplinas y relato de noviazgo de éste con Natalie Talmadge7-, de ilustraciones astronómicas, y de añadidos específicamente dalinianos" (GIBSON, 1985: 420).

Parece que este collage inspiró a Lorca a trabajar sobre el tema, porque poco después escribió un texto de índole surrealista ${ }^{8}$, el Diálogo de la bicicleta de Filadelfia, que finalmente fue publicado bajo el título de El paseo de Buster Keaton. ${ }^{9}$ El manuscrito, fechado en julio de 1925, va dedicado a Dalí. ${ }^{10}$ En una carta escrita en verano de ese año y dirigida a Melchor Fernández Almagro, Lorca explica: "Hago unos diálogos extraños profundísimos de puro superficiales que acaban todos ellos con una canción. Ya tengo hecho La doncella, el marinero y el estudiante, El loco y la loca, El teniente coronel de la Guardia Civil, Diálogo de la bicicleta de Filadelfia y Diálogo de la danza, que hago estos días. Poesía pura. Desnuda. Creo que tienen un gran interés. Son más universales que el resto de mi obra... (que, entre paréntesis, no la encuentro aceptable)"11.

El libro anunciado nunca llegó a realizarse. Algunos de los textos mencionados en la carta fueron publicados en uno de los dos números de la revista Gallo editada por Lorca; dos diálogos se incluyeron en la primera edición del Poema del cante jondo (1931) y otros quedaron incompletos o se perdieron. Y así empieza El paseo de Buster Keaton:

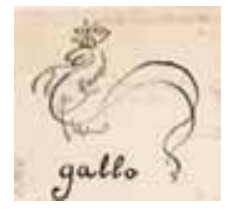

Canta un gallo. Sale Buster Keaton con sus cuatro hijos de la mano. Saca un puñal de madera y los mata. Luego coge una bicicleta y se va $[\ldots] .{ }^{12}$

Román Gubern comenta que el texto está "henchido, como no podía ser de otro modo, de referencias cinéfilas. Se inicia con el canto de un gallo, que sin duda alude al gallo que aparecía en las portadas de los noticiarios de actualidades Pathé, que componían la primera parte de la programación en las salas de cine, precediendo al largometraje" (GUBERN, 1999: 447).

Gibson caracteriza el diálogo lorquiano como un texto telegráfico: "nos sitúa en un escenario norteamericano, sin una sola alusión a España: afueras de Filadelfia; el gallo de las Noticias Pathé; un negro que 'entre las viejas llantas de goma y bidones de gasolina come su sombrero de paja’; la Mujer Moderna, agresivamente li-
7. El casamiento se celebró en 1921. Tuvieron dos hijos varones, James (1922) y Robert (1924). Poco después de haber nacido el segundo hijo, el matrimonio entró en crisis, y en 1932 se acabó con el divorcio. Natalie Talmadge ya había sido actriz antes de trabajar con Keaton.

8. Cabe mencionar que el 18 de abril del mismo año, el poeta francés Louis Aragon dio una conferencia en la Residencia de Estudiantes sobre el surrealismo, pero Lorca estaba fuera de Madrid (GIBSON, 1998, I: 414). Sin embargo, la conferencia fue publicada parcialmente en la revista La Révolution surréaliste, que salió en junio de 1925. El surrealismo fascinó a los estudiantes de la Residencia.

9. "Se puede especular acerca de si este collage heterosexual fue un intencionado mensaje en clave, o una advertencia cordial del pintor al poeta en un momento en que su íntima amistad producía zonas de equívocos sentimentales. Pudo serlo, porque El paseo de Buster Keaton, muy probable fruto de aquel envío, constituyó también una declaración cifrada sobre la crisis de identidad del poeta” (GUBERN, 1999: 447).

10. Las palabras finales de uno de los manuscritos conservados en el archivo García Lorca muestran que el destinatario del diálogo fue Salvador Dalí: “Adiós Dalitaitita / Daliminita / Dalipiruta / Dametira / Deméter / Dalí. [...] Este diálogo conseguido con tan pobres elementos me da une penosa impresión de Buster Keaton. ¿Y a ti? Hijititio. [...] Escríbeme enseguida. / 
En seguida. / En seguida. / En seguida" (GARCÍA LORCA, 1997, II: 844).

En agosto o septiembre del año 1925, Dalí, desde Cataluña, le escribe a

Lorca: "Parece que Buster Kiton [sic] ha hecho una película en el fondo del mar con su sombrerito de paja encima la escafandra de buzo" (GIBSON, 1999: 127). Se refiere a la película The Navigator (El navegante, 1924).

11. En: GARCÍA LORCA, 1997, II: 842.

12. Véase el resumen de Ángela C. ESPINOSA-LEBSACK: "Un gallo

canta: Buster Keaton mata a sus cuatro hijos y decide dar un paseo en bicicleta. En el camino se ve a un negro comiendo su sombrero de paja. Poco después cae de la bicicleta: pero sigue su camino y se encuentra con una estadounidense que le hace sugerencias sexuales. Al final, una joven con cabeza de ruiseñor transita en bicicleta. Cae cuando Buster Keaton se identifica, y éste, tratando de ser galante, pretende resucitarla con un beso; pero de nada sirve."

13. Hay dos películas en las que Keaton va en bicicleta: Our Hospitality (1923) y otra, posterior al texto de Lorca, The General (El maquinista de la General, 1927). Al hablar de Un Chien andalou (1929), tenemos que contar con referencias a esas dos películas de Keaton, pero El paseo de Buster Keaton

(1925) sólo puede dialogar con La ley de la hospitalidad, y no -como lo hace Espinosa-Lebsack en su ensayo citadocon la película de 1927 .

Our Hospitality es una comedia de situación que cuenta la historia de Willie McKay (Buster Keaton), que se ve inmerso en medio de la pelea de clanes de los Canfield y los McKay. berada; la deshumanización de una inmensa sociedad entregada al materialismo." Y el comentarista concluye que "el paseo de bicicleta lorquiano encarna hasta cierto punto los miedos, ansiedades y preocupaciones del propio poeta" (GIBSON, 1998, 1: 420).

La trama del texto lorquiano entreteje una red de alusiones, pero no se refiere a una película en concreto, y además, aporta elementos nuevos. El motivo de la matanza de los cuatro hijos, por ejemplo, no existe en ninguna de las obras de Keaton.

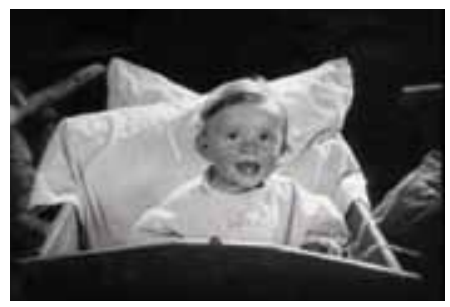

La única fuente matriz del ciclista de Un Chien andalou dentro de la producción cinematográfica de Keaton la encontramos en Our Hospitality (La ley de la hospitalidad), de $1923 \cdot{ }^{13}$ Además, es la película en la que no sólo actúa Natalie Talmadge, la esposa del actor (en el papel de Virginia Canfield), sino también su hijo primogénito James, de un año de edad, llamado en los créditos “Buster Keaton, Jr.”.

Gibson concluye que la imagen evocada de Keaton encaja dentro de une serie de personajes lorquianos cuyo destino está sellado por deseos que nunca podrán realizarse. ${ }^{14} \mathrm{Y}$ uno de los temas principales de la obra lorquiana es sin duda la frustración. El Keaton del diálogo lorquiano mata a sus hijos y consigue deshacerse de sus relaciones familiares para seguir su camino, independiente. “iQué hermosa tarde!" y "Da gusto pasear en bicicleta" exclama el protagonista después de haber cometido el homicidio.

La adoración del actor americano por parte de Lorca refleja un anhelo de libertad para poder vivir sin las fronteras impuestas por la familia, la sociedad y las reglas de la moral. "Escaparse de la España de Primo de Rivera, con su asfixiante moral sexual, su censura, sus tabúes, su constante acoso a anticonformistas e intelectuales y su endurecida legislación para reprimir la homosexualidad; conseguir la independencia económica, incluso, si hace falta, como 'lector' en algún departamento de español extranjero: es la meta fundamental de Lorca en estos momentos en que, a los veintisiete años, sigue dependiendo económicamente de sus padres y apenas ha ganado 
un céntimo con su trabajo" (GIBSON, 1999: 129). Pero queda poca esperanza para que ese deseo se realice. El Keaton lorquiano lo confiesa: "Quisiera ser un cisne. Pero no puedo aunque quisiera". Y parece que su queja todavía hace eco en Cisnes reflejando elefantes, que Dalí pintó en 1937.

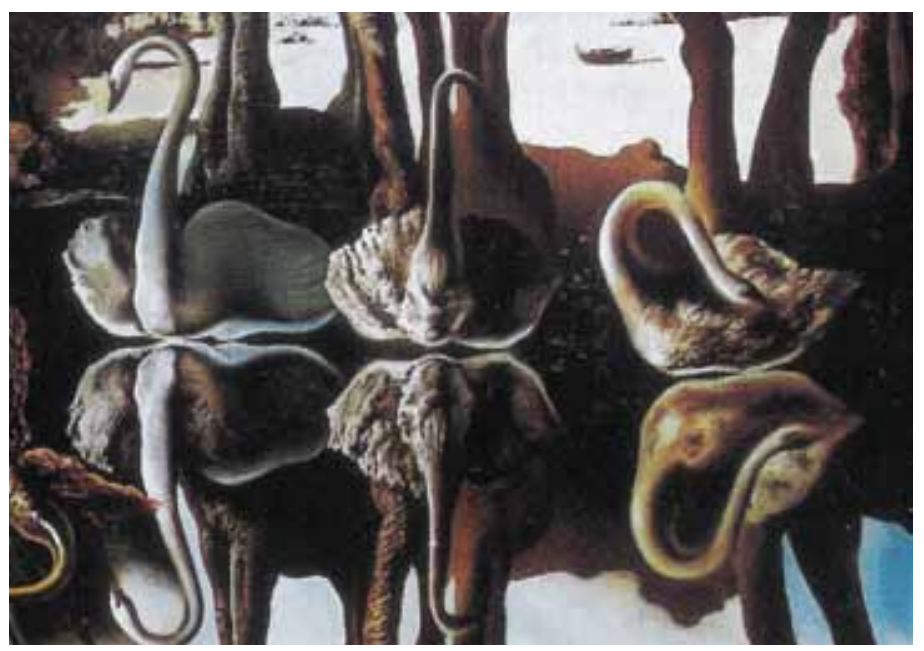

14. "En realidad, este Buster Keaton, aunque sólo someramente esbozado, encaja dentro de la larga serie de personajes lorquianos que quieren ser y no pueden. Que buscan, como Soledad Montoya, su alegría y su persona, pero que no las terminan de encontrar" (GIBSON, 1999: 128).

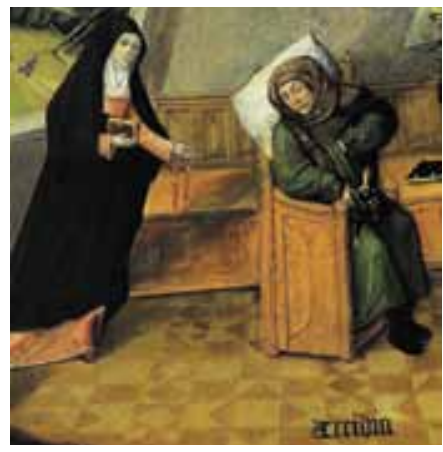

El Bosco (Hieronymus Bosch): "Accidia” (detalle de Los pecados capitales, 1485)

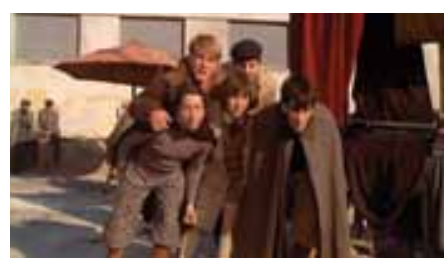

15. La película Amarcord ("me acuer-

do") de Federico Fellini se fundamenta en los recuerdos fictícios de la adolescencia del cineasta, mostrando la vida en una pequeña ciudad italiana de los años treinta. Es una sabrosa crítica a la sociedad con sus valores religiosos y educativos, en la época de la propagación del fascismo.

\section{Sobre pistones y batidores de huevos}

¿Se acuerda? Un adolescente está confesándose. Las preguntas del padre enfocan nada más que en el sexto mandamiento. Titta (Bruno Zanin), un adolescente de dieciséis años, pasa revista a algunos momentos de transgresión. ¿Qué le va a confesar al director espiritual? ¿El encuentro con la ninfómana Gradisca? ¿El sofoco entre los senos de la estanquera? ¿La masturbación colectiva en el coche? No. Sería demasiado atrevido. Mejor decirle al confesor curioso que se había tocado. Una sola vez. Nada más. Sin entrar en detalles. Y decir que se arrepiente... Mientras, el espectador en la sala oscura asiste -como verdadero voyeur- a las sabrosas escenas fellinianas de Amarcord $(1973)^{15}$ en que las posaderas voluminosas de las vendedoras del mercado erotizan, metonímicamente, la bicicleta. 

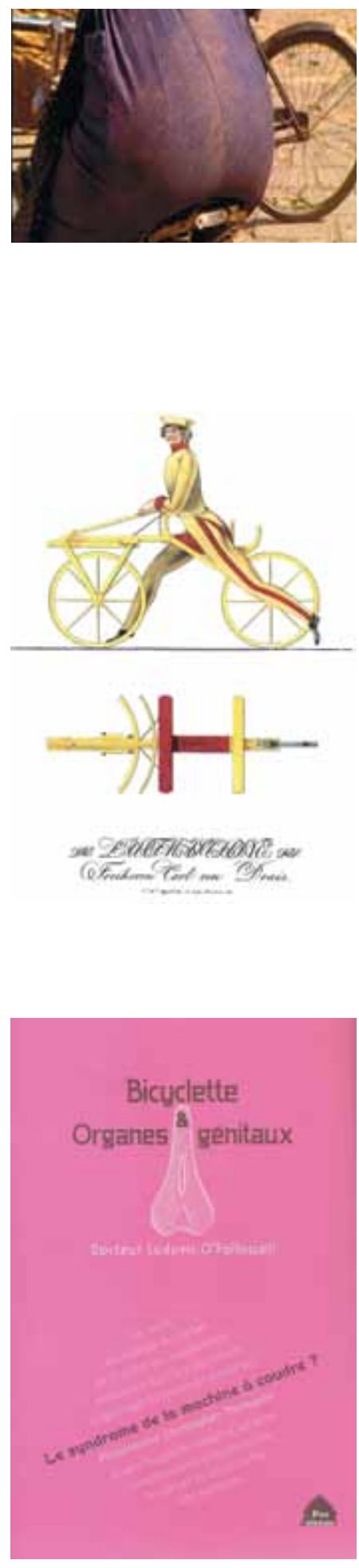
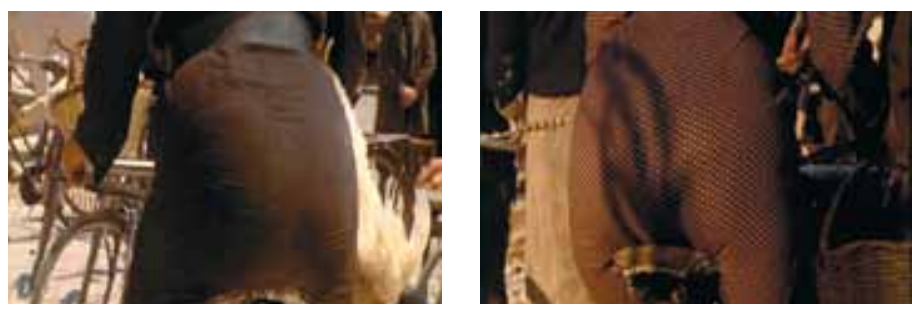

Pero no es así en las películas de Keaton. Parece que en aquel entonces, la bicicleta carecía de cualquier "carga" erótica. Lorca, por lo menos, en El paseo de Buster Keaton, insiste en el carácter unidimensional e inocente del objeto:

Buster Keaton cruza inefable los juncos y el campillo de centeno. El paisaje se achica entre las ruedas de la máquina. La bicicleta tiene una sola dimensión. Puede entrar en los libros y tenderse en el horno de pan. La bicicleta de Buster Keaton no tiene el sillón de caramelo, ni los pedales de azúcar, como quisieran los hombres malos. Es una bicicleta como todas, pero la única empapada de inocencia. Adán y Eva correrían asustados si vieran un vaso lleno de agua, y acariciarían en cambio la bicicleta de Keaton (GARCÍA LORCA, 1997, II: 181-182).

Sin duda alguna, el hecho de que Lorca insista en que la bicicleta de su ídolo cinematográfico sea "la única empapada de inocencia" y que no tenga "el sillón de caramelo, ni los pedales de azúcar" remite a la existencia de bicicletas menos inocentes. Pero ¿quiénes son esos "hombres malos" que convierten el vehículo en un objeto de deseo pecaminoso?

La historia de la bicicleta tiene sus orígenes en 1817. El alemán Karl Freiherr Drais von Sauerbronn (1785-1851) es el inventor de la llamada "Laufmaschine" (máquina de correr), que después se llamó "draisine", precursor del velocípedo y de la bicicleta actual. El vehículo, que en Francia luego fue llamado "la petite reine" (la reina pequeña), le permitía al hombre un desplazamiento autónomo y rápido, por lo cual llegó a tener la nueva invención una popularidad inesperada. Y enseguida surgió la discusión científica sobre las virtudes y desventajas de la máquina con respecto a la salud popular.

En el año 1900, un médico francés, el doctor Ludovic O’Followell, publicó un estudio titulado Bicyclette et organes génitaux, tratando el problema si el auge del ciclismo podría ser la causa del decrecimiento de la raza francesa. En ese estudio se destacan temas como la dolencia del abdomen causada por el abuso del vehículo o su 
influencia sobre la sexualidad y se usan expresiones jurídico-morales para definir si la nueva invención es "criminosa" o "inocente" ${ }^{16} \mathrm{El}$ ensayo aborda también el tema de la máquina de coser y su abuso como instrumento de satisfacción sexual para la mujer, y sin negar que el uso de la bicicleta pueda provocar los mismos efectos, el médico francés le da la preferencia porque el ciclismo se practica al aire libre. ${ }^{17}$

$\mathrm{Al}$ insistir Lorca en la inocencia de la bicicleta de Keaton, tenemos la confirmación indirecta de que la opinión pública la consideraba un objeto erótico -igual que la máquina de coser, que también aparece en el texto lorquiano. ${ }^{18}$

En el campo literario, hay un ensayo revelador del autor italiano Edmondo De Amicis: La tentazione della bicicletta (1906), en el cual "ir en bicicleta" ya no se llama un paseo con "la petite reine", sino un "acoplamiento con la brujita" ${ }^{19}$ De Amicis describe en su bozzetto cómo la bicicleta llegó a tener tanta popularidad en Italia que no sólo los jóvenes, sino también los ciudadanos más honorables de avanzada edad se sentían fascinados por la nueva invención. Por no querer pasar por ridículo resiste, pero se siente aun más ridículo porque llega a ser casi el único sin hacer uso de la nueva invención. El autor termina su texto con el consejo irónico para los gordos de su generación que ceden a la tentación para no tener que pasar como él por el infierno de la frustración. ${ }^{2}$

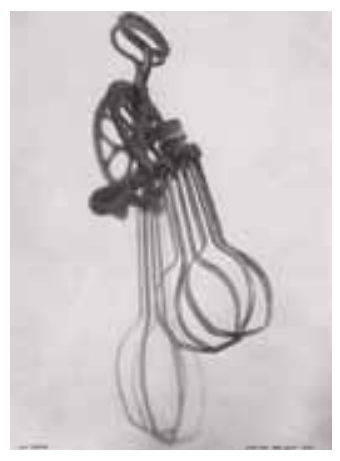

En un contexto más amplio hay que mencionar a Man Ray. El artista de Filadelfia pretende que "todo puede ser transformado, deformado o eliminado por la luz, que es tan versátil como el pincel, ni más ni menos" (en: HEITING, 2004: 170). Su obra La Femme (1920), por ejemplo, no es nada más que la foto de un batidor de huevos transformado por el título. Emmanuelle de l'Ecotais comenta que "en sus cuadros realizados en Nueva York, Man Ray había mostrado su intención de mostrar de forma sensible, con medios fotográficos, la vida de los objetos, su independencia, su capacidad se significar algo distinto de aquello para lo que habían sido fabricados" (idem, 2004: 154-155).

La erotización del objeto será más evidente en otra obra fotográfica de Ray, Erotique dévoilée (1933). La combinación de una rueda mecánica con un desnudo femenino entabla una mutua contami-
16. “[...] nous avons souvent, très souvent, interrogé les femmes cyclistes afin de connaître d'elles l'influence de la bicyclette sur leur appétit sexuel. Sur les quatre-vingt-trois cas de notre enquête, il y a huit fois diminution, huit fois augmentation, toutes les autres femmes n'ont constaté aucune modification et encore celles qui ont accusé une différence en plus ou en moins avouaient facilement ou que ces désirs plus vifs étaient dus non à la promenade même, mais à la compagnie des personnes avec lesquelles elles cyclaient, ou que leurs désirs calmés résultaient d'un trop long effort pour arriver au but de la promenade.

Or, de quelque façon que vienne la fatigue, qu'il s'agisse d'un effort sportif quelconque, bicyclette, marche excessive, etc., si celle-ci terrasse et endort, ce n'est pas l'exercice qu'il faut accuser, mais l'excès de cet exercice" (O'FOLLOWELL, 2009: 152-153). “La lecture de ces cas ne m'ayant point convaincu, je n'accueillis dans la suite qu'avec une certaine méfiance à ma consultation la déclaration de deux jeunes gens qui incriminaient la bicyclette: ayant fait appel à leur franchise, ils m'avouèrent que cette dernière était plus innocente qu'ils n'avaient prétendu” (idem, 2009: 110).

17. Une femme à la machine à coudre reste dans une atmosphère confinée et doit avoir les yeux sur son travail. La position occasionne une pression sur les organes pelviens. Avec son mouvement court, rapide, limité aux muscles de la cuisse et du jarret sans déplacement du sujet, la machine à coudre ne peut être comparée à la bicyclette, qui met en action tout le membre inférieur et qui est utilisée en plein air. [...] / Depuis le moment o fut 


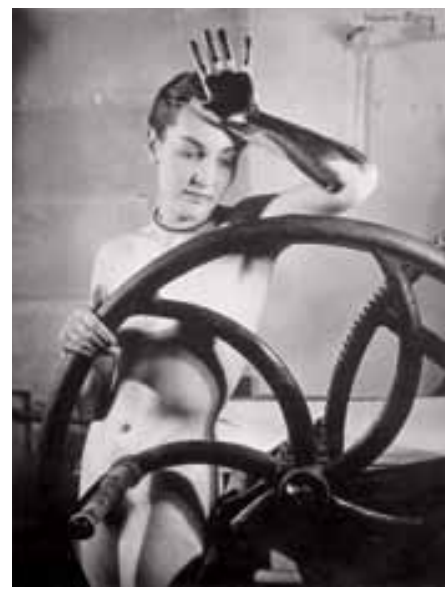

nación semántica: Meret Oppenheim se convierte en una mujerobjeto en tanto que la rueda se erotiza.

Otro observador del fenómeno es Georges Bataille, cuyos textos eróticos pregonan una percepción metonímica de la máquina. En el ensayo L'Anus solaire (El ano solar), escrito en 1927 y publicado solamente en 1931, el pensador francés dice que existen dos movimientos principales, que son el movimiento rotativo y el movimiento sexual. Su combinación se exprime por las ruedas y pistones de una locomotora. ${ }^{21}$

El ejemplo pionero en la historia del cine que juega con la erotización de los objetos es la película Ballet mécanique (1924) de Fernad Léger y Dudley Murphy. Ray era colaborador de esa obra experimental. El cortometraje tan adorado por Buñuel junta tomas de mujeres (Kiki de Montparnasse) con escenas de máquinas y utensilios de cocina en movimiento. Además, carece de un argumento narrativo -como Le Chien andalou.

rédigé par nous cet article, nous avons vu avec joie de savants médecins ou chirurgiens argumenter comme nous et faire surtout de ce que l'exercice de la bicyclette se pratique en plein air, la raison majeure pour laquelle on ne saurait comparer la bicyclette et la machine à coudre. / Certes, pour une femme qui le veut bien, pédaler quelque peu suffit à procurer une satisfaction génitale. Voici des faits. M. Verchère connaît une jeune dame bicycliste qui lui a avoué s'offrir à volonté, sur sa bicyclette, deux ou trois séances à intervalles voulus, de masturbation complète" (idem, 2009: 76-79).

de l'apprentissage, vous ramasserez des bûches et ferez rire le commun des mortels ; mais vous échapperez à dix ans de tentations et de regrets qui, tous ensemble, vous feraient plus de mal que quelques côtes cassées et seraient bien plus humiliants que la risée publique. Suivez le conseil de cet inconscient: « les mains sur le guidon et l'âme au vent » (A. Oriani), ou vous finirez par vous en mordre les doigts et par donner votre âme au diable" (idem, 2009: 36-37).

composée de roues et de pistons. / Ces deux mouvements se transforment l'un en l'autre réciproquement"

(BATAILLE, 1970: 82).
18. En El paseo de Buster Keaton se define la sociedad americana por la connotación erótica de la máquina de coser: "A lo lejos se ve Filadelfia. / Los habitantes de esta urbe ya saben que el viejo poema de la máquina Singer puede circular entre las grandes rosas de los invernaderos, auque no podrán comprender nunca qué sutilísima diferencia poética existe entre una taza de té caliente y otra taza de té frío. / A lo lejos, brilla Filadefia" (GARCÍA LORCA, 1997, II: 182).

19. "Mais la plus dure épreuve vint ensuite, quand, sous mes propres yeux, les amis et les connaissances de mon âge commencèrent à s'accoupler avec la petite sorcière" (DE AMICIS, 2009: 25). Cito la reciente traducción francesa del ensayo, establecida por Olivier Favier, La Tentation de la bicyclette.
21. "Les deux principaux mouvements sont le mouvement rotatif et le mouvement sexuel, dont la combinaison s'exprime par une locomotive 

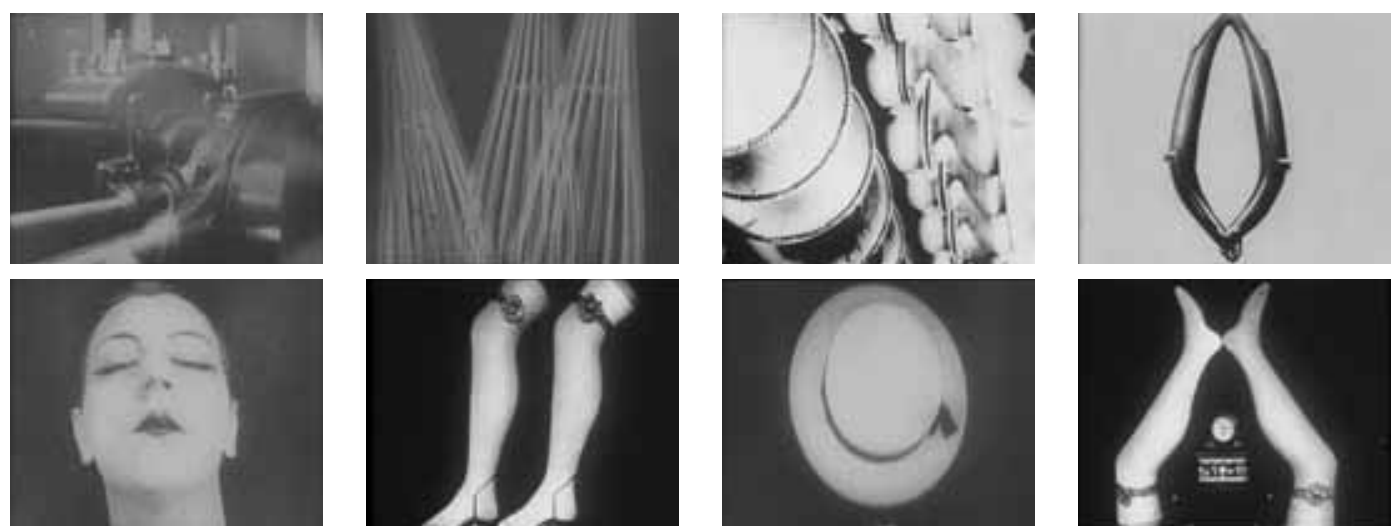

El tema ha persistido hasta el cine contemporáneo. El inicio de la película brasileña Lavoura arcaica (2001) de Luiz Fernando Carvalho, por ejemplo, muestra un cuerpo masculino en convulsiones eróticas sobre un fondo óptico y sonoro de una locomotora en movimiento.

Las películas de Keaton, sin embargo, se caracterizan todavía por lo contrario: versan -no sin cierta ironía- sobre el tema de la inocencia. En The General (El maquinista de la General, 1926), el desmañado Keaton tiene en gran estima a su novia y, a la vez, a su locomotora; las dos son los objetos de su casto deseo, pero toda la película se desarrolla en un ambiente asexuado, y es como si la observancia del sexto mandamiento por parte del protagonista convirtiese a la mujer en un tabú (casi) intocable.
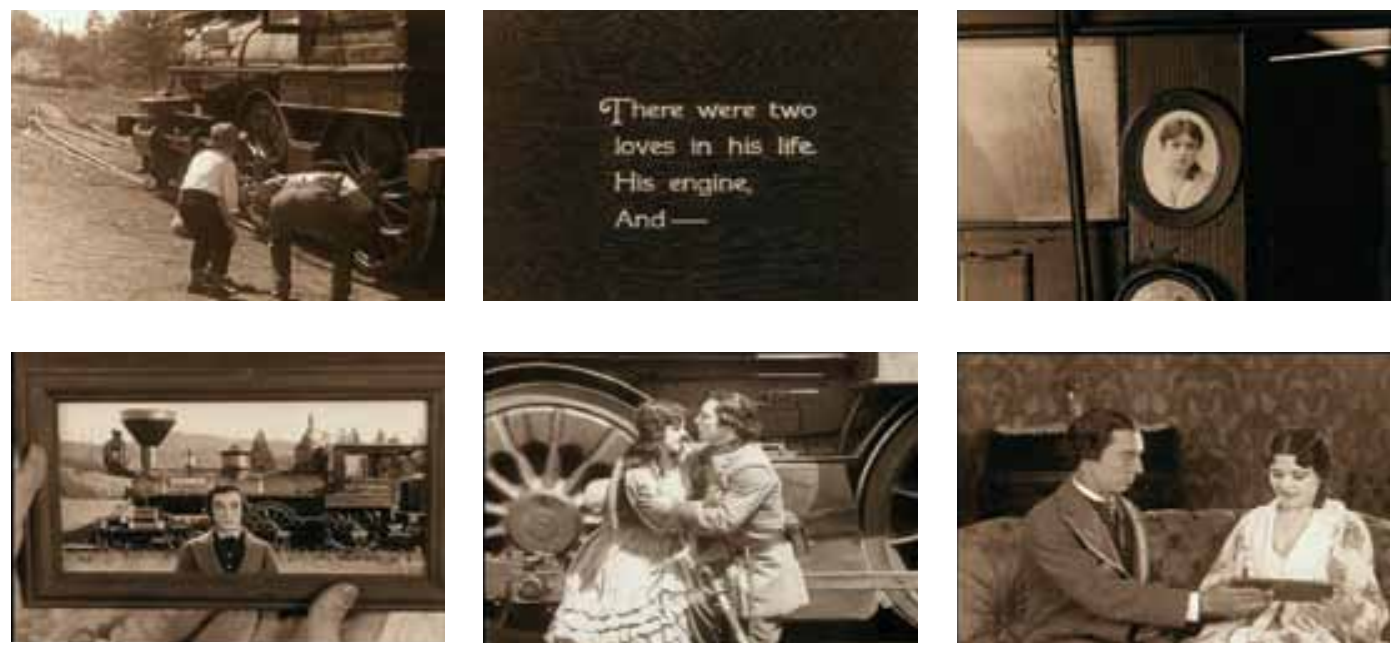

El maquinista de la General, aunque posterior al texto lorquiano, es un ejemplo que se incorpora a la lista de los personajes interpretados por el actor americano con quien Lorca podía haberse identificado: se equipara al ciclista de El paseo de Buster Keaton. 


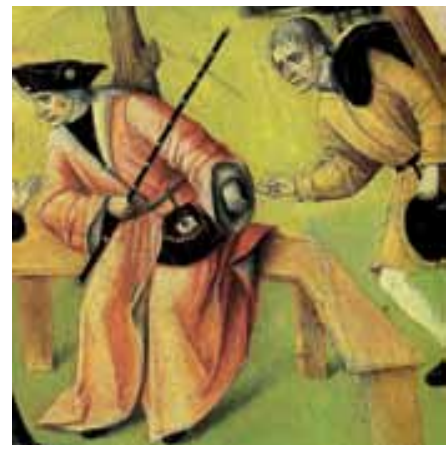

El Bosco (Hieronymus Bosch): "Avaritia” (detalle de Los pecados capitales, 1485)

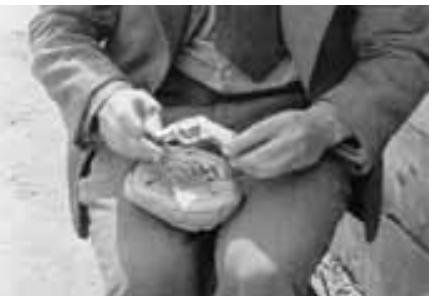

22.En Nueva York sube a un wagón de mercancías que va al Oeste. Allí trabaja como vaquero en un rancho, sin tener ni la menor idea del oficio. La hija del ranchero le muestra su simpatía, pero el corazón de Friendless está en Brown Eyes (Ojos Castaños), una vaquita. El vaquero hace todo para

\section{Sobre vacas y cazadores de mariposas}

Generalmente, los papeles interpretados por Keaton son protagonistas "empapados de inocencia”. En Go West (El rey de los cowboys, 1925), el actor americano interpreta a Friendless, un chico pobre y desocupado, que se ve obligado a ir por el mundo en busca de trabajo. ${ }^{22}$

Al llegar a la estación de mercancías de Nueva York, encuentra un bolso de mano bordado con varios objetos sui generis -cigarillos, maquillaje y un pequeño portamonedas vacío. En el fondo del bolso descubre un minúsculo revólver femenino, que le servirá de arma de fuego durante su expedición para el Oeste americano. El futuro cowboy, equipado con esos objetos femeninos, parece ser el modelo perfecto del ciclista interpretado por Pierre Batcheff.

Además, Friendless, que no está acostumbrado al movimiento urbano de una metrópoli, se cae en las calles de Nueva York y los transeúntes pasan por encima de él. Se repite también el motivo de la caída.

Luego hay una escena en la cual un coche atropella al chico, lo que recuerda la escena con Fany Massan del cortometraje buñuelino.
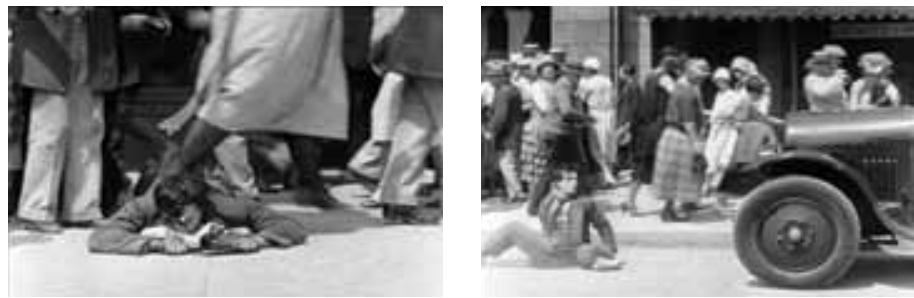

En el rancho, la hija (antagonista de la vaca) le pide a Friendless que le saque una astilla de madera de su mano. El primer plano con la navaja se asocia con varias escenas de Un Chien andalou (la mano del prólogo, la mano cortada, la mano con las hormigas, la navaja con la que se corta el ojo).

salvar el animal del matadero. Huye con su vaca $-\mathrm{y}$ con ella se escapa también una manada de toros. Los animales causan la mayor confusión en el centro de Los Ángeles, pero Friendless, con la ayuda de Brown Eyes, consigue mantener la situación bajo control. El ranchero le queda muy agradecido y Friendless podría pedir la mano de la hija del ranchero. Pero enmarañado en su soledad, ni se le ocurre tal idea, y como recompensa pide la vaca. 
Y finalmente, hay escenas con una vaca dentro de la casa, motivo que reaparecerá en las películas posteriores de Buñuel.
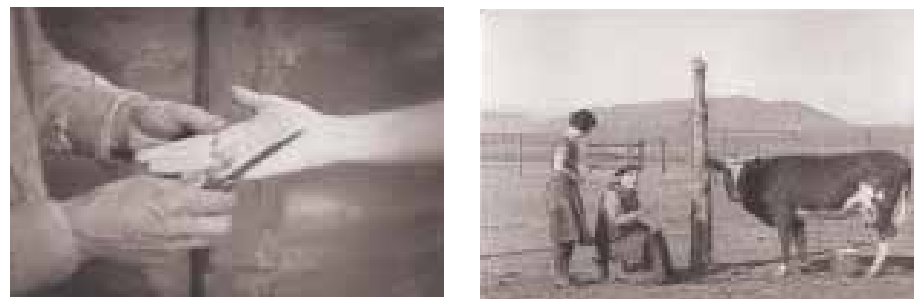

La castidad absolutamente asexuada de Friendless dio origen a un poema burlón de Rafael Alberti, que se titula "Buster Keaton busca por el bosque a su novia que es una verdadera vaca”. El poema, que se refiere al rey de los cowboys, fue publicado en 1929 en el libro Yo era un tonto y lo que he visto me ha hecho dos tontos (ALBERTI, 1977: 140-142), pero no es imposible que Lorca lo haya conocido ya en la época cuando escribió su diálogo sobre el actor americano.

En el primer verso del poema de Alberti, el protagonista cuenta las cuatro huellas que dejó la vaca:

$1,2,3$ y 4

En estas cuatro huellas no caben mis zapatos.

Si en estas cuatro huellas no caben mis zapatos, ¿de quién son estas cuatro huellas?

¿De un tiburón, de un elefante recién nacido o de un pato?

¿De una pulga o de una codorniz?

Tanto el texto de Alberti como el de Lorca empiezan con un conteo. El cowboy albertiano cuenta las huellas que dejó la vaquita, mientras el Keaton lorquiano verifica si ha realmente matado a todos sus cuatro hijos, borrando así las huellas de su prole.

Los dos textos dedicados al gran actor del cine mudo americano tienen en común que no se refieren a una película específica de Keaton. Franz-Josef Albersmeier ${ }^{23}$ ya ha señalado que el poema de Alberti abre también el diálogo referencial con otras películas: atribuye la "carrera de ciclista" a Our Hospitality (1923) y el "smoking" a Sherlock Junior (El moderno Sherlock Holmes, 1924):

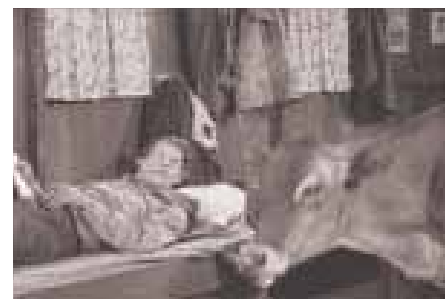


24. Albersmeier interpreta el nombre de la vaca (Georgina en vez de Brown

Eyes) como una alusión a Gold Rush (La quimera del oro, 1925), de Charles Chaplin.

25. La película acaba con un desenlace feliz: el protagonista consigue dar vuelta a la rueda de su destino y se casa con la hija del cacique.

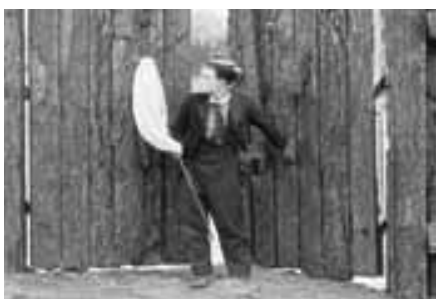

\section{¡Georgina!}

Ahora que te faltaba un solo cuerno

para doctorarte en la verdaderamente útil carrera de ciclista y adquirir una gorra de cartero.

$[\ldots]$

Compadécete del smoking que te busca y te llora entre los aguaceros y del sombrero hongo que tiernamente

te presiente de mata en mata. ${ }^{24}$

El cowboy enamorado de la vaca del poema de Alberti y el ciclista afeminado de Un Chien andalou son personajes que representan una existencia marginada. Son ridículos. Y no nos puede extrañar que Lorca, al identificarse con Keaton, fuese el perro andaluz burlado.

Además de Go West, hay otra película de Keaton que ha dejado sus huellas en las obras de Lorca, Dalí y Buñuel: The Paleface (El rostro pálido, 1921)

Hablemos primero de Lorca. En El paseo de Buster Keaton, el protagonista "corre detrás de dos grandes mariposas grises. Va como loca, a medio milímetro del sueño" (GARCÍA LORCA, 1997: 182). Esta indicación escénica abre el dialogismo intertextual con el cortometraje en el cual Keaton interpreta a un cazador de mariposas, pero cuando el cazador entra en el recinto de una tribu india, se convierte en una "mariposa cazada": los indios lo atan a un poste de tormento para matarlo: ${ }^{25}$
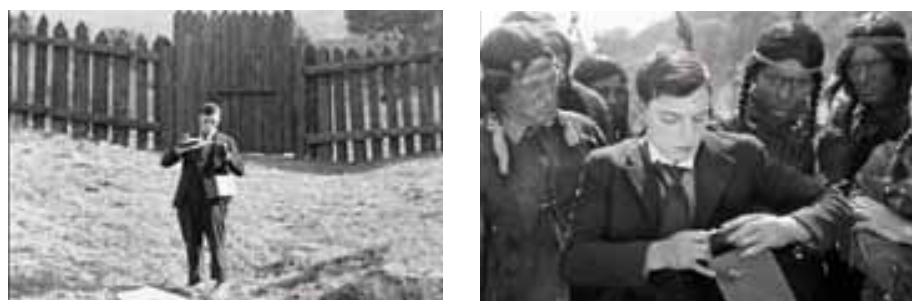

En Poeta en Nueva York reaparecerán las mariposas junto a un poema de manifiesto homoerotismo. La "Oda a Walt Whitman" amalgama la cabeza del autor americano con el insecto llamativo (GRACÍA LORCA, 1997 BIS: 218): 


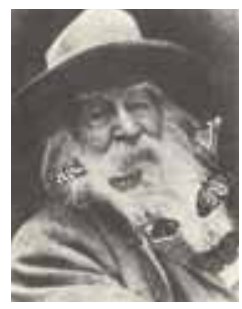

Ni un solo momento, viejo hermoso Walt Whitman, he dejado de ver tu barba llena de mariposas, ni tus hombros de pana gastados por la luna, ni tus muslos de Apolo virginal, ni tu voz como una columna de ceniza; anciano hermoso como la niebla.

En la obra del pintor catalán, las mariposas aparecen en los arcanos del Tarot de Dalí, donde circundan al Loco y al Enamorado.

$\mathrm{Al}$ combinar los elementos asociados, el Keaton lorquiano, cazador de mariposas, que anda "como loca [sic]" por el mundo, se define con los epítetos de "enamorado" y "homosexual" -igual que el ciclista, antes de caerse de la bicicleta.

Además, al comparar The Paleface con Un Chien andalou, hacemos constar otras concordancias reveladoras:

Primero, es la caja del cazador de mariposas que llama la atención, y me parece posible que sea la figura matriz de la caja misteriosa
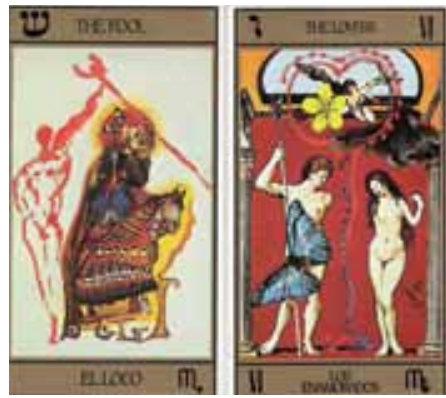
del ciclista. Y segundo, vale la pena comparar la estructura de las escenas finales.

Comparando las dos series de fotos correspondientes a los dos cortometrajes en discusión, hay que preguntarse seriamente si el final de Un Chien andalou no es nada más que una copia estructural del desenlace de The Paleface:
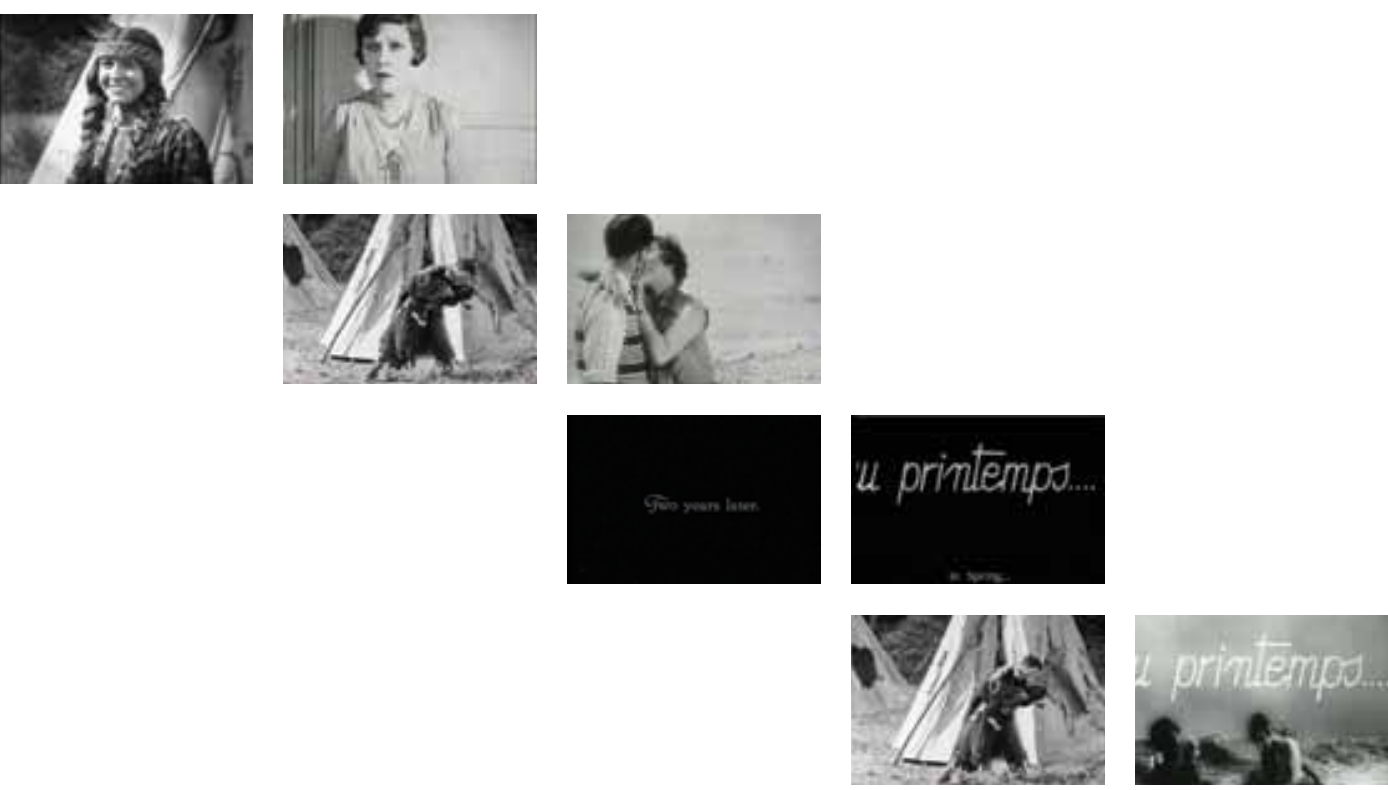


\section{Sobre esclavinas y placeres iluminados}

Román Gubern, en su artículo "Las fuentes de Un perro andaluz en la obra de Dalî”, señala que el personaje del ciclista procede de Dalí, remitiendo al cuadro Los placeres iluminados, de $1929 .{ }^{26}$ Se trata de una obra múltiple con tres cuadros puestos en un marco, estatuas y figuras humanas, dentro de un paisaje surrealista. En la pintura central reconocemos un autorretrato de Dalí, conocido como la cabeza del "gran masturbador". A la derecha, en el primer plano, hay un cuadro menor representando un paisaje de ciclistas barbudos, vestidos de gris y cada uno con una piedra blanca sobre la cabeza. Lo que llama la atención es la posición paralela de "los placeres iluminados", que son, entre otros, el ciclismo y la masturbación.

El motivo del ciclismo se repite en varias obras de Dalí, lo que nos permite enfocar el tema dentro de un contexto más amplio. La obra talvez más reveladora para nuestros propósitos es el guión Babaouo $^{27}$ que Dalí publicó por primera vez en París, en 1932, con la idea de completar la trilogía de películas surrealistas, con L’Âge d'or (1930) y Un Chien andalou..$^{28}$

\footnotetext{
26. "El rótulo « Ocho años después » inaugura la atípica intriga que sucede al prólogo de Un perro andaluz. Un hombre en bicicleta avanza por una calle, ornado por una afeminada cofia y manteletes, y portando una cajita sobre su pecho. Buñuel reconoció que esta imagen procedió de Dalí. Imagen misteriosa, hasta el punto de que Raymond Durgnat no ocultó
}

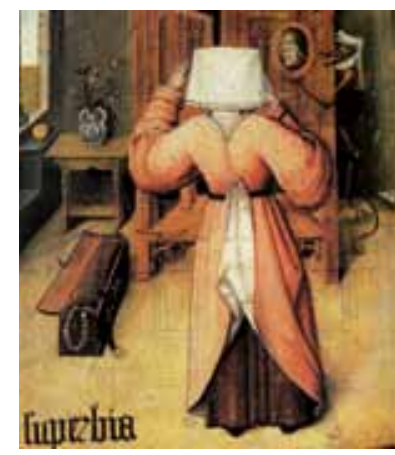

El Bosco (H. Bosch): "Superbia” (detalle de Los pecados capitales, 1485)
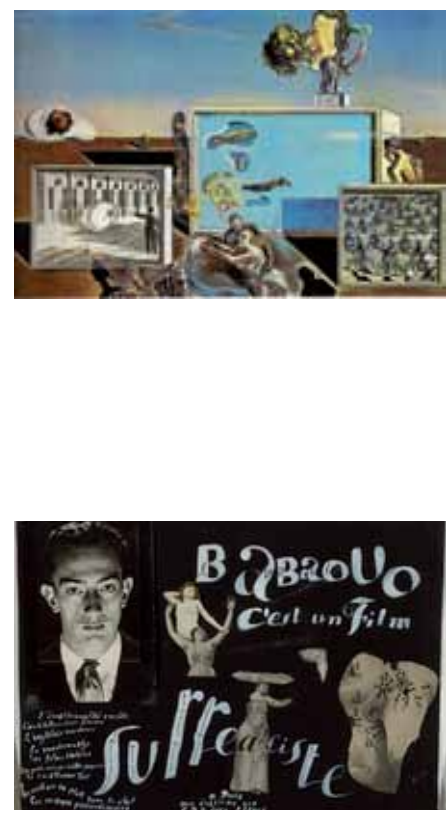

27. “ Hay una edición bilingüe del guión (francés y español), con ocho ilustraciones y un prólogo del propio Dalí, de 1978. El proyecto cinematográfico Babaouo fue realizado por el director catalán Manuel Cussó-Ferrer en el año 2000. 
El guión informa que "la acción de este film transcurre en 1934 en cualquier país de Europa, durante la guerra civil” (DALÍ, 1978: 43).29

Lo que nos interesa aquí en particular, son las descripciones de los ciclistas que aparecen a lo largo de la obra. En su camino a Portugal, Babaouo sigue "por une calle absolutamente seca y llega a una gran plaza de ciclistas que se entrecruzan lentamente. Llevan los ojos vendados y transportan una piedra voluminosa sobre la cabeza. La célebre y pequeña esclavina blanca, muy limpia está prendida en sus hombros. / Babaouo atraviesa la plaza, pasando con precaución entre los ciclistas" (DALÍ, 1978: 57-59).30
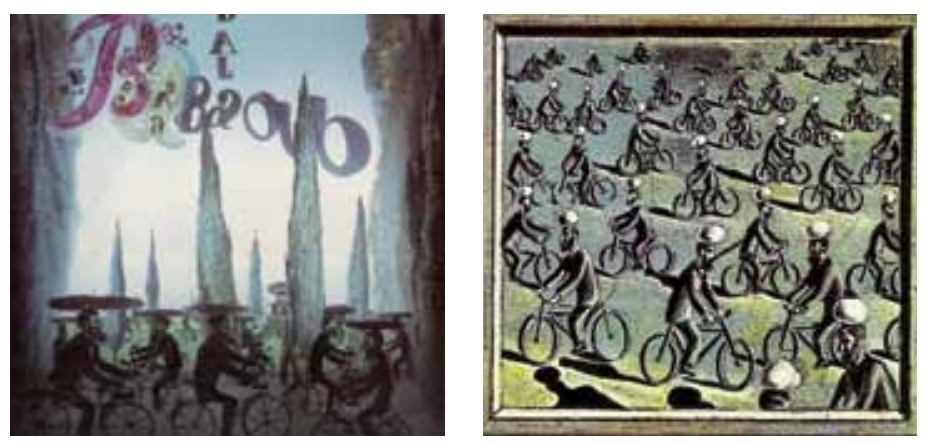

29. Babaouo se divierte en un hotel de lujo cuando recibe una carta de Matilde Ibáñez pidiéndole socorro por estar sola en su castillo de Portugal desde hace tres días. El protagonista se pone inmediatamente en camino para ir a Portugal. Cuando llega al castillo, Matilde se arroja en sus brazos. Los dos quieren acostarse frente a una "cosa amortajada", pero llega la madre de Matilde llorando, en compañía de algunos amigos de la familia. Cuando se acercan al presumible cadáver, Matilde y un chico sostienen "el paquete", el uno por los pies y la otra por la cabeza, lo columpian y lo lanzan sobre sobre la señora que se cae al suelo. Babalouo y Matilde se escapan del castillo en coche. Matilde se abalanza sobre el hombro de Babaouo y lo muerde en la nuca, de manera que el joven suelta el volante y el coche se estrella contra un árbol. Matilde se muere y Babalouo se salva, ciego y con quemaduras.

Sigue un "epílogo", que sucede años después, en un pueblo bretón de pescadores. Babaouo, ya envejecido y con la vista recuperada, pasa el tiempo pintando en un ambiente de amenaza
28. Un "Compendio de una historia crítica del cine" escrito por Dalí precede la edición del guión. El pregonero catalán del surrealismo define sus ideas fundamentales sobre el cine, pasando revista y comentando películas, directores y actores de las primeras décadas del siglo XX, para llegar a la siguiente conclusión: "En 1929, Buñuel y yo escribimos el guión de Un Chien andalou, y en 1930 el guión de L'Âge d'or. Son los dos primeros films surrealistas. / Aparte los films de propaganda revolucionaria comunista, que se justifican por su valor propagandístico, lo que cabe esperar del surrealismo y lo que cabría esperar de cierto cine denominado cómico es todo lo que merece ser considerado" (DALÍ, 1978: 48). y explosiones. Al terminar, va por el pueblo en bicicleta, cuando lo matan. Cambio. En un teatro, frente a un telón daliniano, un bailarín y una mujer efectúan una danza. Después entran en escena una arpista y unos ciclistas, cada uno con un pan sobre la cabeza y los ojos vendados. El espectáculo está interceptado por motociclistas y por "máquinas de coser y aspiradoras que caen desde el telar y se estrellan contra el escenario, mientras el telón se cierra lentamente" (DALÍ, 1978: 143). 


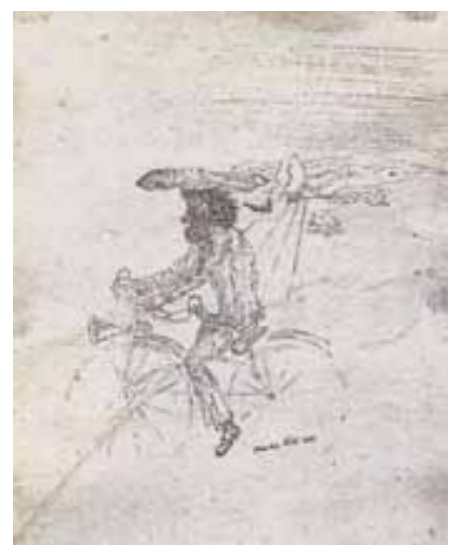

30. Los ciclistas vuelven a aparecer en la última parte del guión, que describe lo que acontece en un teatro: "El telón se levanta de nuevo al son del tango 'Renacimiento'. El escenario está lleno de ciclistas que, con un pan sobre la cabeza y los ojos vendados se entrecruzan con gran lentitud con parejas de bailarines de tango" (idem, 1978: 139).
La esclavina vuelve a aparecer en la segunda parte, al describir el vestuario de Babaouo-pintor: "Se quita la chaqueta blanca y la sustituye por otra negra que la anciana ha ido a buscar en un armario donde estaba cuidadosamente doblada. Le ayuda a ponérsela y le prende en los hombros, mediante unos imperdibles, la tan conocida pequeña esclavina de tela blanca. Le venda los ojos con una servilleta y, con ayuda de una correa que pasa por debajo de la barbilla, le sujeta un largo pan sobre la cabeza. Babaouo monta en una bicicleta y parte con gran lentitud, con una leve sonrisa de hombre comprensivo" (DALÍ, 1978: 119-121). Atraviesa la ciudad en bicicleta y se topa con un grupo de músicos tocando tangos. Se arranca la venda que le cubre los ojos. Pasa por delante de un coche cuando, desde el interior del vehículo, alguien dispara tiros sobre el ciclista. Babaouo se cae muerto.

La piedra o el pan sobre la cabeza (cuyo significado no vamos a discutir aquí) corresponde a la manera como están presentados los ciclistas en Los placeres iluminados.

Hay otro detalle que me llama la atención y que me parece digno de un comentario: es la prescripción de "la célebre y pequeña esclavina", en vez de decir simplemente "una esclavina". Dalí le da tanta importancia a esa prenda de vestir (la "pèlerine" del texto original francés) que es oportuno hacerle caso.

En primer lugar, hay que saber lo que es una esclavina. El Diccionario del español actual la define como una "capa corta que llega aproximadamente hasta el codo y que constituye una prenda suelta o forma parte de otra, especialmente de un abrigo o capa” (SECO, 1999, I: 1923). Da como ejemplos el traje de novia, la indumentaria eclesiástica o taurina (pieza sobrepuesta de la parte superior de la capa o capote). El Diccionario de autoridades añade que se trata de una prenda usada en las romerías y que la palabra se deriva del substantivo "esclavo". Predomina, pues, la definición para una prenda de vestir que designa una función sumisa, servidora.

Hablando de la esclavina, Dalí se refiere a un modelo concreto. ¿Pero cuál?31Supongamos que sea el ciclista de Un Chien andalou. 
Podemos determinar una serie de elementos paralelos entre las dos obras:

- En ambas hay un ciclista estrambóticamente vestido.

- Los dos caen de la bicicleta.

- La banda sonora prevista para Babaouo se compone de un tango (Renacimiento) y de fragmentos de una ópera de Richard Wagner (Tannhäuser). Ese elemento adicional corresponde exactamente al fondo musical del estreno de Un Chien andalou en París. Sabemos que Buñuel se aprovechó de un gramófono y que los discos que tenía a disposición eran un tango argentino y una aria de Wagner. ${ }^{32}$

Los puntos en común son tantos que los dibujos dalinianos para Babaouo también revelan los secretos del ciclista andaluz. Hacemos constar que los hombres que andan pedaleando por el mundo están sexualmente excitados. El ciclismo se revela como el deporte de la excitación por excelencia.

Además, el movimiento de las piernas corresponde exactamente al de los pistones que Bataille había descrito en L'Anus solaire. La connotación erótica es innegable y vale tanto para Babalouo como para el ciclista andaluz, sumiso y servidor.
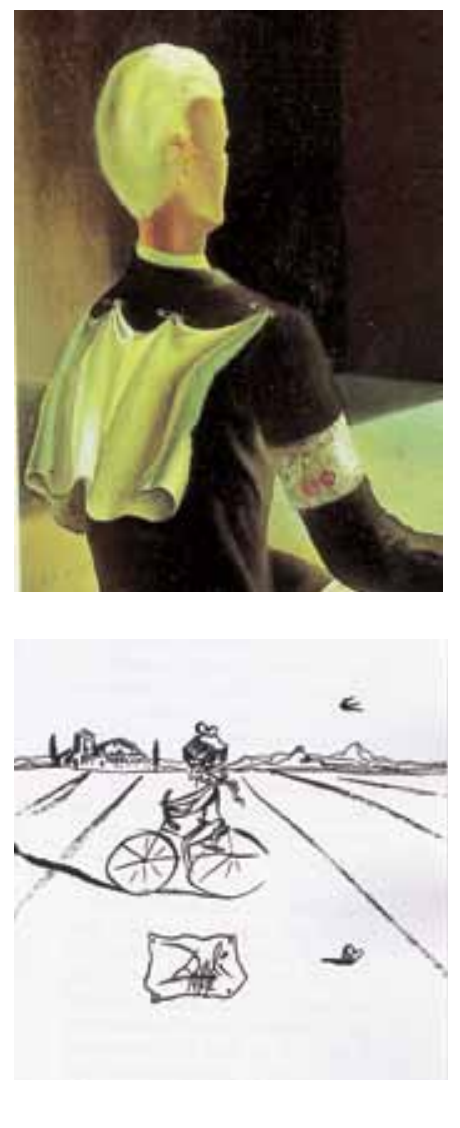

31. Esta prenda de vestir aparece también en la pintura de Dalí. Véase el detalle de Alucinación parcialSeis apariciones de Lenin sobre un piano (1931).tango" (idem, 1978: 139).

32 "[La película] se estrenó por la noche y asistió le tout Paris. Yo como precaución llevaba -eso lo he contado muchas veces- piedras en los bolsillos. Se proyectaba la película y yo manejaba el gramófono. Arbitrariamente ponía aquí un tango argentino, allá Tristán e Isolda" (PÉREZ TURRENT / DE LA COLINA, 1993: 25). 


\section{Sobre ruedas y toros}

La imagen del círculo o de la rueda siempre ha estado cargada de valores simbólicos, y el concepto de la ROTA FORTUNAE ya existía en los textos de Cicerón o del filósofo Boecio. La tradicional rueda de la Fortuna -que se conoce sobre todo por el décimo arcano del tarotmuestra el destino del ser humano en cuatro fases diferentes. En una iluminación del Codex buranus o Carmina burana (siglo XII), por ejemplo, hay a la izquierda un hombre ascendiendo al poder y el texto en la margen de la página dice en latín: "REGNABO” (reinaré). Arriba, en su trono, está sentado el Rey con todas sus insignias, y el texto al lado dice: "REGNO" (reino). A la derecha reconocemos a un ser humano que ha perdido su posición de poder y que se cae en los abismos: "REGNAVI" (reiné). Y abajo, finalmente, está el pobre hombre maldito para quien la rueda se ha convertido en instrumento de tortura: "SUM SINE REGNO" (no tengo reino). La rueda como instrumento de tortura también aparece a menudo en los cuadros de El Bosco.

En la histórica obra de la Real Academia Española, el DiccioNARIO DE AUTORIDADES publicado entre 1726 y 1737, se define la "rueda" como "máchina, orbiculár y rotunda, que facilmente gyra, dá vueltas y rueda, de donde tomó el nombre"; y bajo "rueda de la fortuna" el diccionario nos informa que "en sentido figurado vale la inconstancia y poca estabilidad de los sucessos y providencia humana" (RAE, 1976, III: 650).

En un contexto cultural español hay que tomar en cuenta otro tipo de rueda simbólica, una que no gira, pero que sí hace girar alrededor de un eje central: me refiero al ruedo, palabra que designa el "círculo de la plaza de toros destinado a la lidia" (SECO, 1999, II: 3989), en que los aficionados o curiosos circundan el espectáculo de

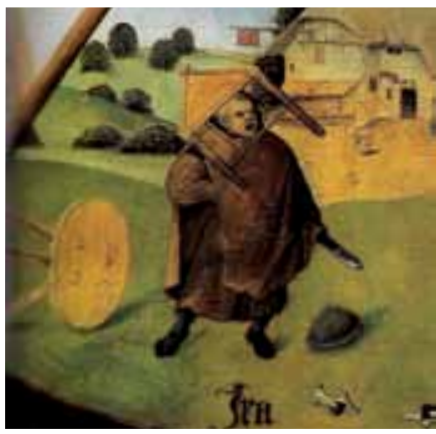

El Bosco (Hieronymus Bosch): "Ira" (detalle de Los pecados capitales, 1485 )
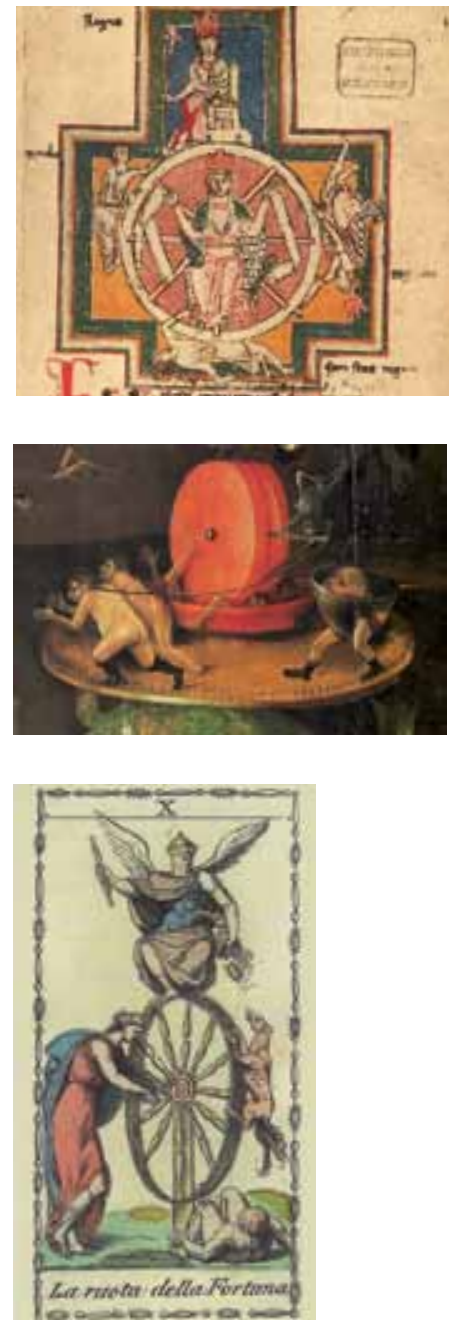
la muerte. Este término taurino adopta una configuración simbólica diferente, bien más allá de los momentos discutidos del ascenso al poder, el mantenerse en equilibrio en una posición poderosa, la caída y la miseria. El círculo de aficionados se interesa por el espectáculo fúnebre, cuyo eje no es la vida ni la diosa Fortuna que mueve el destino de los hombres, sino la muerte. El centro del ruedo taurino es el lugar donde se mata. Allí la concepción abstracta de la muerte se concretiza visiblemente en el cuerpo del toro agonizante. El ruedo taurino es "la rueda de la Muerte".

Para Picasso, la corrida es uno de los temas favoritos. En una serie de grabados intitulada La tauromaquia (1957), el pintor malagueño usa el color negro, lo que destaca el ambiente letal de la ceremonia.
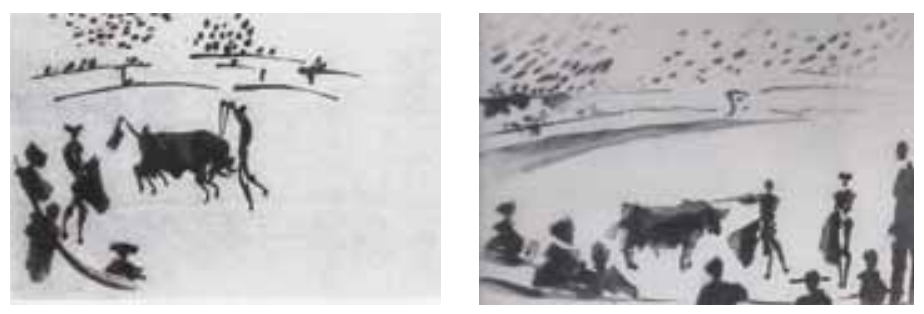

Ramón del Valle-Inclán (1869-1936) es el autor de una trilogía de obras literarias que se llama "el ruedo ibérico". 33 La imagen del ruedo da para entender que la realidad española -esperpéntica- gira alrededor de un eje marcado por la muerte.

En Un Chien andalou, hay una escena en que los transeúntes forman un círculo alrededor de una chica y una mano cortada. Los paralelos entre esta escena y el ruedo taurino se imponen: la mano
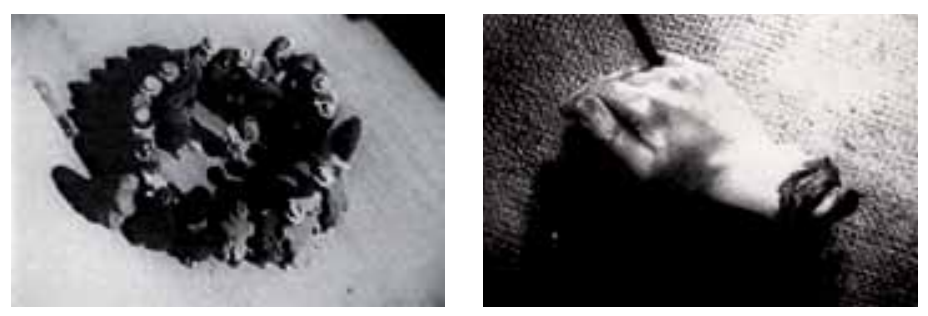

cortada en el suelo ocupa el lugar del toro, y la chica (Fano Messan) con su extraña elegancia y su corte de pelo masculino ocupa el lugar del matador. ${ }^{34}$ En vez de la muleta, sujeta con las manos una caja rayada (la misma que lleva el ciclista). Se juntan en esta escena los elementos esenciales de la corrida: están también los aficionados
33. La trilogía conformada por los textos La corte de los milagros (1927), Viva mi dueño (1928) y Baza de espadas (póstuma) define la visión “esperpéntica” que el autor tiene de la realidad española.

34. Cf. Buñuel: "Fano Messan, la que en la película juega con la mano cortada, era una muchacha que en Montparnasse venía a veces a tomar un café con nosotros, vestida de chico, hasta que un día se presentó vestida de mujer” (PÉREZ TURRENT / DE LA COLINA, 1993: 24).
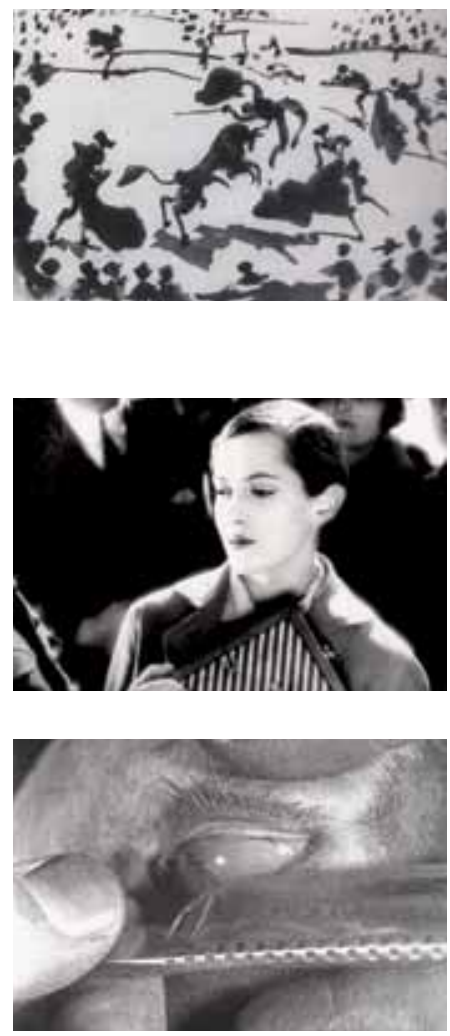
35 "Dans la passe tauromachique aussi bien que dans le coït, il y a cette montée vers la plénitude (approche du taureau) puis le paroxysme (le taureau s'engouffrant dans la cape en frôlant de sa corne le ventre de l'homme aux pieds rivés) ; enfin la séparation des deux acteurs, la divergence après l'intime contact, la chute,

le déchirement. [...] Comme dans l'acte amoureux avant la crise finale,

l'on reste suspendu, dans l'angoisse que cela cesse, l'extase émerveillée que cela néanmoins continue. La répétition, de même que dans les gestes du coït, multiplie à chaque fois l'ivresse [...] C'est alors que l'ovation du public éclate et couronne le tout, telle la détente de la jouissance : et sans doute serait-on fondé à parler, au sens admis autant qu'au sens le plus trivial du mot, de l'ovation comme d'une « décharge ", - baisse du potentiel nerveux, pareille à une tombée de fièvre, en même temps qu'éjaculation qui a pour sperme les bravos" (LEIRIS, 1981: 50).

36. Bataille había publicado su primera novela bajo el pseudónimo de Lord Auch.

37. Manuel Granero y Valls, torero español (1902-1022): "El 7 de mayo de 1922 toreaba en Madrid junto a Juan

Luis de la Rosa y Marcial Lalanda. "El segundo toro de Granero, llamado Pocapena, de la ganadería del Duque de Veragua, le cogió por el muslo y lo dejó sentado, apoyada la espalda en las tablas. Entonces le asestó una cornada que penetró por el ojo derecho del torero y le causó la muerte" (Wikipedia). que forman el ruedo, asistiendo al espectáculo fúnebre. Es una danza macabra: Thánatos besa los pies de Eros.

El tema de amor y muerte en la tauromaquia ha sido tratado por varios autores. Pienso en primer lugar en el ensayo de Michel Leiris, Miroir de la tauromachie (1981), que en le capítulo "L’amour et la tauromachie" relaciona el arte de torear con el arte de amar, la lidia taurina con el coito. 35

Lo que Leiris formula en los años ochenta, ya existía en la literatura (clandestina) de los años veinte: me refiero a la primera novela de Georges Bataille, L'Histoire de l'œil (Historia del ojo, 1928)..$^{36} \mathrm{El}$ texto del autor francés -que sin duda ninguna circulaba entre los surrealistas de París- describe al final una corrida de toros en la que murió Manuel Granero. ${ }^{37}$

En el capítulo intitulado "L’CEil de Granero" (El ojo de Granero), un narrador ficticio en primera persona cuenta los acontecimientos ocurridos en la plaza de toros de $\mathrm{Madrid}^{8}{ }^{8}$, pero los combina con una historia paralela, marcada por un erotismo sorprendente: la muerte del primer toro por Granero se equipara con la excitación sexual de Simone, la chica que acompaña al narrador, de tal manera que los dos se retiran a los retretes de la plaza para dar rienda suelta a sus deseos incontrolables. Vuelven a sus lugares y encuentran sobre el asiento de Simone un plato con los testículos del toro muerto, lo que aun más excita a la joven ninfómana. Prisionera de los deseos más obscenos y de la intransigente voluntad de realizarlos en el acto, Simone y sus amigos asisten a la muerte de Granero, matado por una cornada en el ojo derecho:

\section{[...] l'une des cornes enfonça} l'œil droit et la tête. La clameur atterrée des arènes coïncida avec le spasme de Simone. Soulevée de la dalle de pierre, elle chancela et tomba, le soleil l'aveuglait, elle saignait du nez. Quelques hommes se précipitèrent, s'emparèrent de Granero.

La foule dans les arènes était tout entière debout. L'œil droit du cadavre pendait (BATAILLE, 1979: 79).

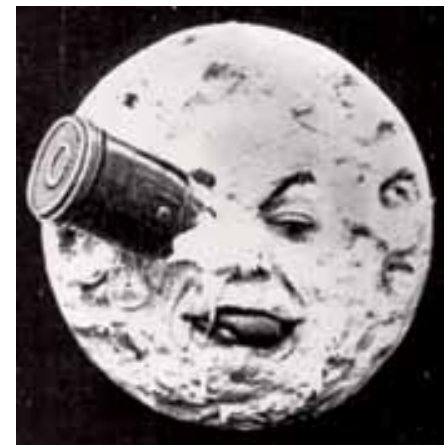


El texto establece un paralelismo entre la muerte del torero y el orgasmo de Simone, dando importancia a la protagonista sangrando de la nariz y relegando los acontecimientos históricos a segundo plano. El atrevimiento literario de Bataille ha dejado sus huellas entre los aficionados del surrealismo parisiense, y particularmente en las obras de Buñuel y de Dalí.

L'Histoire de l'œeil y Un Chien andalou tienen por lo menos dos elementos importantes en común: un ojo perforado y un ambiente regido por la sexualidad. De acuerdo: la reacción de la mujer ( $\mathrm{Si}-$ mone Mareuil) a los asedios sexuales en la película no refleja el comportamiento desenvuelto de la protagonista de Bataille, pero de alguna manera le corresponde. La imagen que tenemos de la Simone de la obra de Bataille no es pictórica; es puramente construida y está arraigada en la tradición literaria de las obras del Marqués de Sade. Comparado con eso, el cortometraje de Buñuel y de Dalí mantiene el carácter de las tradiciones de una España marcada por el catolicismo que por una parte reprime la sexualidad, pero por otra parte ostenta escenas de violación y muerte como reliquias.

El ojo tachado y la mano cortada son dos figuras de la castración que en el ámbito cultural ibérico ejemplifican -siguiendo la tradición pictórica de El Bosco- el castigo por haber visto los frutos del jardín de las delicias o por haberlos tocado.

Pablo Picasso, pintor asiduo de escenas taurinas, confeccionó una escultura titulada Cabeza de Toro (1942), que se compone de un manillar y un sillín de bicicleta. Dos campos semánticos se entrecruzan: el de la corrida y el del ciclismo.
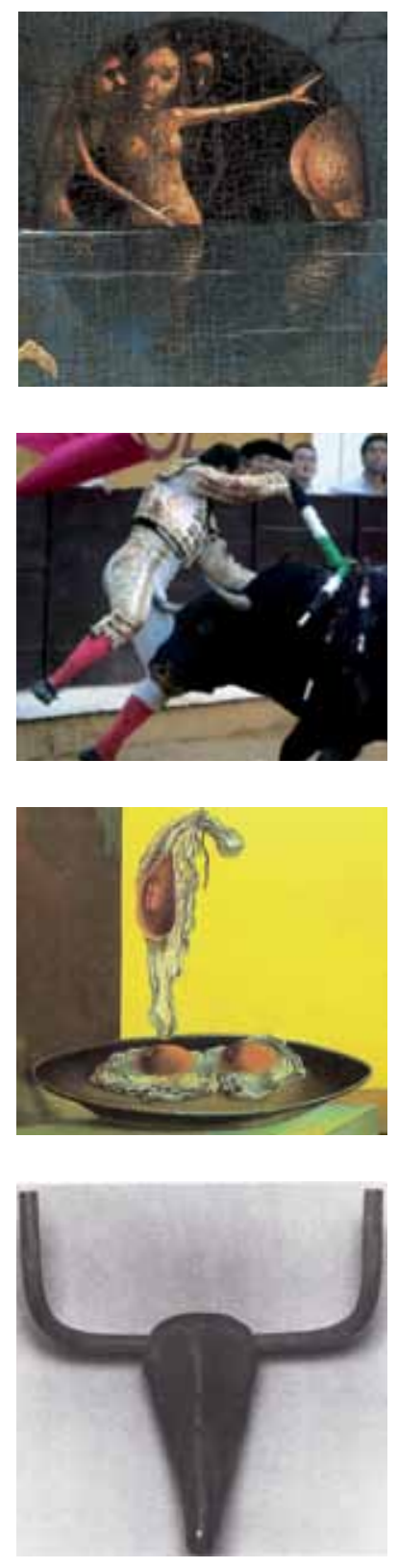

38. "Le 7 mai 1922, La Rosa, Lalanda

et Granero devaient toréer aux arènes de Madrid. Belmonte au Mexique, Lalanda et Granero étaient les grands matadors d'Espagne" (BATAILLE, 1979: 73). 


\section{Sobre caídas y cajas a rayas}

Volvamos a El paseo de Buster Keaton quien anda feliz por el mundo, después de haber matado a sus hijos. El lugar, a pesar de definirse americano, no es menos irreal que aquel de los cuadros de El Bosco. El ciclista pasa por los alrededores de una Filadelfia fantástica ${ }^{39}$ y encuentra, "entre las viejas llantas de goma y bidones de gasolina" a un negro que "come su sombrero de paja". Cruza "los juncos y el campillo de centeno y cae de la bicicleta mientras exclama: "!Ay amor, amor!" Entonces, el Buster Keaton lorquiano, "con sus ojos de culo de vaso", entra en un jardín en el que pasa por la hierba una chica americana "con los ojos de celuloide". El encuentro no sale bien. La americana se lleva un susto al enterarse con quién está, se desmaya y cae de su bicicleta. Buster Keaton intenta consolarla, mientras luce, en el horizonte de Filadelfia, "la estrella rutilante de los policías" (GRACÍA LORCA, 1997: II: 184) -escena que en nuestra lectura remite a la represión de la homosexualidad.

Hay varios elementos de escarnio de Un Chien andalou que tienen su fuente de inspiración en este texto lorquiano. La Filadelfia del diálogo se ha convertido en la ciudad de París no menos fantástica, por estar a orillas del mar. Además, la mujer con la cual el ciclista se encuentra es una francesa que lo invita a su casa. Y en las dos obras no hay desenlace feliz para el protagonista.

En 1929, Dalí pintó una de sus obras famosas, Le grand masturbateur, en la que podemos reconocer fácilmente la cabeza del propio pintor. Está con los ojos cerrados, pero de su cabeza sale una mujer, también de ojos cerrados, cuya boca está a la altura de las partes genitales de un torso masculino. El gran masturbador está en la posición del ciclista caído de su vehículo. Dalí -a pesar de su ti-

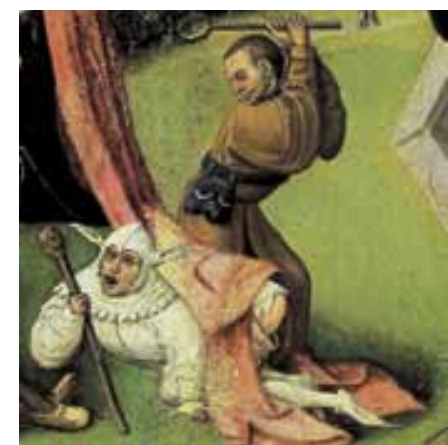

El Bosco (H. Bosch): "Luxuria"

(detalle de Los pecados capitales, 1485)

39. Me parece posible que el nombre de la ciudad de Filadelfia contenga una connotación homoerótica ("filos" en griego, significa "amigo" o "amante").

40. "José Bello insistiría en [...] lo que más le había llamando la atención de Dalí de los primeros momentos de su amistad era su extrema timidez. El catalán estaba 'literalmente enfermo' de ella, la persona más inhibida que Bello había conocido jamás. Se ruborizaba a menudo, no decía apenas nada y mostraba un total desinterés por las mujeres. Uno de los contemporáneos de Salvador en San Fernando, el escultor Cristino Mallo, estaba igualmente impresionado: 'En esa época lo sorprendente de Dalí, que más tarde haría cosas tan escandalosas, era, sobre todo, que era sumamente vergonzoso'. 'El Dalí de ese período se parecía a Buster Keaton -opinaba otro amigo, Rafael Sánchze Ventura-. Era de una timidez enfermiza, todo lo contrario de lo que sería después"' (GIBSON, 1999: 97). 
midez atestiguada ${ }^{40}$ - siempre tuvo esa frescura de nombrar las cosas mientras Lorca hacía todo para disimular lo que podía considerarse escandaloso.41 No es que no hable de temas íntimos, pero en aquella época lo hacía con la mayor discreción posible. El guión Viaje a la luna (1929), por ejemplo, refleja el viaje de Lorca a Nueva York (motivado por la ruptura con Dalí y con la intención de tomar distancia de Europa y de los autores de Un Chien andalou) y es un ejemplo modelo de tal procedimiento. Podemos considerarlo un texto muy personal del autor en el que presenta lo más íntimo de su existencia, pero de un modo tan cifrado que las verdaderas preocupaciones personales resultan casi inaccesibles para el gran público.

Una fuente de claves interpretativas, tanto para la obra de Lorca como también para algunos cuadros de Dalí, es la obra de El Bosco. El hecho de que en Viaje a la luna el pájaro sea un símbolo masculino y la rana se refiera sexo femenino tiene su explicación en las obras que Lorca y sus amigos tanto admiraban en el Prado.

En la escena final de El paseo de Buster Keaton, en la que se desmaya una joven sexualmente frustrada, a pesar de la presencia de su ídolo de la pantalla, hay un gramófono diciendo que "en América, no hay ruiseñores". Me parece lícito interpretar que la chica desilusionada dice a su manera que en América no hay hombres verdaderos.

El Keaton de Lorca se funda en los personajes desmañados y asexuales que el actor americano solía interpretar, y aparece en la ficción literaria como si Lorca no quisiera aceptar el casamiento de Keaton con Natalie Talmadge. La reacción de la chica americana corresponde mutatis mutandis a la frustración del autor.

El joven con la cabeza sumergida en las aguas de El jardín de las delicias se asemeja al hombre que se ha caído de la bicicleta. Sin embargo, el personaje de El Bosco, con un pájaro saliendo de un voluminoso fruto rojo entre las piernas, muestra sus obsesiones sexuales, mientras el ciclista del cortometraje no lo hace. La caja misteriosa está cerrada.

En casi todas las películas de Buñuel hay algún objeto cuyo contenido es secreto. Son verdaderas cajas de Pandora porque al abrirlas, cada vez sale un objeto diferente. El ciclista parece entregar una encomienda, como si fuera el mensajero de una tienda de moda.

Pero no es así. La película no tiene ningún hilo narrativo. $\mathrm{Si}$ en $U n$ Chien andalou hubiera una pretensión diegética, la mujer debería sacar de la cajita la mano cortada que el policía había guardado en ella.
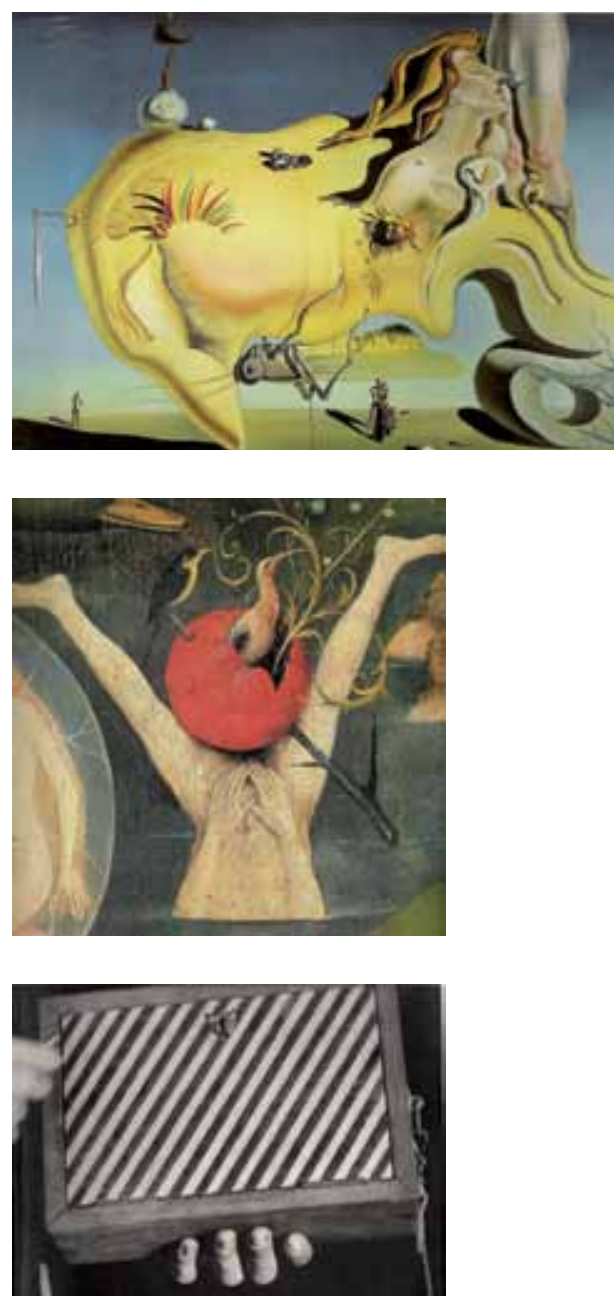

41. Con su obra Parfois je crache sur le portrait de ma mère (1929), por ejemplo, Dalí manifiesta su disposición a armar el escándalo público y a romper con el tabú

42. "La Joven se desmaya y cae de la bicicleta. Sus piernas a listas tiemblan en el césped como dos cebras agonizantes" (GARCÍA LORCA, 1997: 184). 
43. Compárese el procedimiento técnico y el contexto metafórico en Viaje a la luna (MELCHIOR, 9008: 62-66): sale "un muchacho desnudo en traje de baño de grandes cuadros blancos y negros”, y el guión lorquiano indica "gran plano del traje de cuadros sobre una doble exposición de un pez".
Gibson pretende que la caja es otro elemento que refuerza la vinculación entre El paseo de Buster Keaton y Un Chien andalou por tener "las mismas rayas a listas que las medias de una de las muchachas del texto de Lorca (GIBSON, 1999: 248).42 En nuestra lectura, el significado de la caja misteriosa es más amplio:

En ella se guardan todos los anhelos ligados al pecado de la carne. Está repleta de imágenes prohibidas para menores de dieciocho años, mujeres desnudas, senos fellinianos, traseros voluminosos sobre bicicletas, erecciones y otras fantasías eróticas. La caja rayada de blanco y negro tapa lo que no se podía ni ver ni nombrar en aquella España católica marcada por una represión moralista. Guarda los sueños de poder seguir viviendo en París, capital del pecado, de ver, tocar y gozar los frutos del jardín de las delicias. Es un tapabocas, una venda sobre los ojos cerrados para ver en la imaginación los objetos de deseo.

Una breve secuencia de Un Chien andalou ilustra nuestra conclusión. En gran plano hay una doble exposición³ de la caja con las partes íntimas del ciclista. Aquí la caja no es nada más que una tapa cinematográfica del sexo. En ella, simbólicamente, se concentran las flechas de escarnio que Buñuel y Dalí lanzaron contra Lorca.
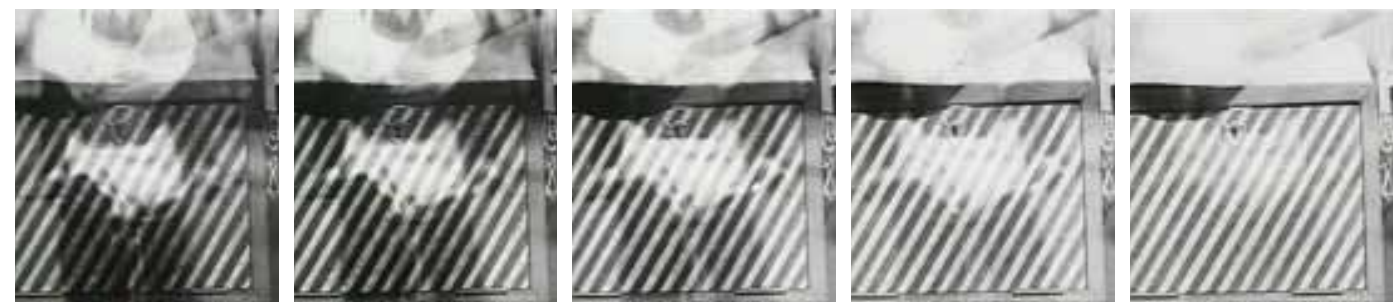

Pero el ataque contra el ex-compañero de la Residencia de Madrid no fue un ajuste de cuentas público; fulano y mengano no tenían que entender. Sin embargo, Buñuel rotuló la caja con la palabra clave que Lorca comprendió perfectamente: dentro hay un perro andaluz que sale para pasearse por la sala del cine. La caja también es la pantalla. 


\section{Bibliografía}

ALBERSMEIER, Franz-Josef. 2001. Theater, Film, Literatur in Spanien. Literaturgeschichte als integrierte Mediengeschichte. Berlin: Erich Schmidt.

ALBERTI, Rafael. 1977. Sobre los ángeles. Sermones y moradas. Yo era un tonto y lo que he visto me ha hecho dos tontos. Con los zapatos puestos tengo que morir. Barcelona: Seix Barral.

BATAILLE, Georges. 1970. Euvres complètes. I. Premiers écrits. 1922-1940. Paris: Gallimard.

BATAILLE, Georges. 1979. Histoire de l'œeil. Paris: Gallimard. BUÑUEL, Luis. 1982. Obra literaria. Introducción y notas de Agustín Sánchez Vidal. Zaragoza: Heraldo de Aragón.

DALÍ, Salvador.1978. Babaouo. Edición bilingüe. Traducción y notas de Esteban Riambau Saurí. Barcelona: Labor.

DE AMICIS, Edmondo. 2009. La tentation de la bicyclette. Préfacé et traduit de l'italien par Olivier Favier. Paris: Les Éditions du Sonneur.

ESPINOSA-LEBSACK, Angela. 2007. Ambigüedades mecánicas y temáticas en El paseo de Buster Keaton. http://www. geocities.com/espinoslabsack/cineysurrealismo.

GARCÍA LORCA, Federico. 1997. Obras completas. 4 tomos. Edición de Miguel García-Posada. Barcelona: Galaxia Gutenberg / Círculo de Lectores.

GARCÍA LORCA, Federico. 1997 BIS. Poeta en Nueva York. Edición de María Clementa Millán. Madrid: Cátedra.

GIBSON, Ian. 1998. Federico García Lorca: 1. De Fuente Vaqueros a Nueva York (1898-1929); 2. De Nueva York a Fuente Grande (1929-1936). Barcelona: Crítica.

GIBSON, Ian. 1999. Lorca-Dalí: el amor que no pudo ser. La apasionante y trágica amistad de dos colosos de la España del siglo XX. Barcelona, Plaza \& Janés.

GIBSON, Ian. 2004. Dalí joven, Dalí genial. Madrid: Santillana/ Aguilar.

GUBERN, Román. 1999. Proyector de luna: la generación del 27 y el cine. Barcelona: Anagrama.

HEITING, Manfred (ed.). 2004. Man Ray. Ensayos de Emmanuelle de l'Ecotais y Katherine Ware. Köln: Taschen.

LEIRIS, Michel. 1981. Miroir de la tauromachie. Paris: Fata Morgana. 
MELCHIOR, Reto. 2008. Viaje a la luna: uma biografia em projeção. Análise de um roteiro de Federico García Lorca. São Paulo: Perspectiva.

O'FOLLOWELL, Ludovic. 2009. Bicyclette et organes génitaux. Présentation de Christopher Thompson. Toulouse: Le Pas d'oiseau. Ola Pepín! Dalí, Lorca y Buñuel en la Residencia de Estudiantes. Ensayos escritos con motivo de las jornadas organizadas en mayo de 2004 para conmemorar el centenario del nacimiento de Salvador Dalí y en homenaje a José Bello Lasierra cuando cumplía cien años. 2007. Madrid: Residencia de Estudiantes / Barcelona: Fundació Caixa Catalunya.

PÉREZ TURRENT, Tomás / DE LA COLINA, José. 1993. Buñuel por Buñuel. Madrid: Plot.

REAL ACADEMIA ESPAÑOLA (RAE). 1976. Diccionario de autoridades. Edición facsímil de la edición de 1726 (tomo I), 1732 (tomo II) y 1737 (tomo III). Madrid: Gredos.

Salvador Dalí y Federico García Lorca: la persistencia de la memoria. 2004. Libro editado con motivo de la exposición (12 de noviembre de 2004 - 30 de enero de 2005). Barcelona: Viena Ediciones / Museu d'Història de Catalunya.

SÁNCHEZ VIDAL, Agustín. 1988. Buñuel, Lorca, Dalí el enigma sin fin. Barcelona: Planeta.

SECO, Manuel / ANDRÉS, Olimpia / RAMOS, Gabino. 1999. Diccionario del español actual. 2 tomos. Madrid: Aguilar. 


\section{Filmografía de Buster Keaton (hasta 1929)}

1920: The Saphead (Pasión y boda de Pamplinas); Convict 13

(Convicto 13); The Scarecrow (El espantapájaros);

Neighbors (La vecina de Pamplinas)

1921: One Week (Una semana); The Playhouse (El gran

espectáculo); The Boat (La barca); The Haunted House

(La casa encantada); Hard Luck (Pamplinas nació en día 13);

The High Sign (El guardaespaldas); The Goat

(El chivo); The Paleface (El rostro pálido)

1922: Cops (La mudanza); My Wife's Relations (Las relaciones con mi mujer); The Blacksmith (El herrero); The Frozen North (El polo norte); Daydreams (Sueños imposibles);

The Electric House (La casa eléctrica)

1923: The Balloonatic (El aeronauta); The Love Nest

(Nido de amor); Three Ages (Las tres edades);

Our Hospitality (La ley de la hospitalidad)

1924: The Navigator (El navegante); Sherlock Jr.

(El moderno Sherlock Holmes)

1925: Go West (El rey de los cowboys); Seven Chances

1926: The General (El maquinista de la General); Battling Butler

1927: College (El colegial)

1928: Steamboat Bill, Jr. (El héroe del río); The Cameraman

(El cameraman)

1929: Spit Marriage (El comparsa) 